Türkiye Jeoloji Bülteni
Geological Bulletin of Turkey
$63(2020) 277-302$
doi: $10.25288 / \mathrm{tjb} .589144$

\title{
Biga Yarımadası'nda Sakarya Zonunun Prekambriyen Metamorfik Kayaları; Geç Ediyakaran Gondwanaland Aktif Kıta Kenarı
}

Pre-Cambrian Metamorphic Rocks of the Sakarya Zone in the Biga Peninsula; Late Ediacaran Gondwanaland Active Continental Margin

\section{Erdinç Yiğitbaş $^{* *} \mathbb{D}$, İsmail Onur Tunç ${ }^{2} \mathbb{D}$}

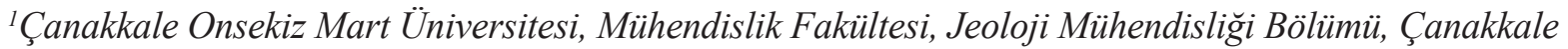 ${ }^{2}$ Çanakkale Onsekiz Mart Üniversitesi, Ezine MYO, Mimarlık ve Şehir Planlama Bölümü, Ezine, Çanakkale}

\footnotetext{
• Geliş/Received: 09.07.2019 • • Düzeltilmiş Metin Geliş/Revised Manuscript Received: 06.03.2020 • • Kabul/Accepted: 20.03.2020 • Çevrimiçi Yayın/Available online: 03.04.2020 • Baski/Printed: 20.06.2020

Araşstırma Makalesi/Research Article Türkiye Jeol. Bül. / Geol. Bull. Turkey
}

Öz: Biga Yarımadası'nda Jura öncesi yaşlı metamorfik kayalar; metamorfizma derecesi, deformasyon nitelikleri ve gelişme ortamları bakımından birbirlerinden belirgin farklılıklar gösteren üç ana tektonostratigrafik birlik olarak değerlendirilebilir. Bunlar; 1) Kazdağ Birliği, 2) Kalabak Birliği, 3) Karakaya Birliği’dir. Kazdağ Birliği, Biga Yarımadası'nın görülür temelinde, Kazdağ Masifi'nin ileri derecede metamorfik çekirdek kayalarını oluşturur. Kalabak ve Karakaya birlikleri bu ileri derecede metamorfik temel üzerinde birer karma (kompozit) tektonik dilim olarak yer alır ve metamorfik masifin daha düşük dereceli dış zarflarını oluşturur.

$\mathrm{Bu}$ makalenin ana konusu olan Kalabak Birliği; Dedetepe Formasyonu, Sazak Formasyonu, Torasan Formasyonu ve tüm bu birimleri kesen Devoniyen yaşlı Çamlık metagranodiyoritinden oluşmaktadır. Kazdağ Masifi'nde metamorfik çekirdeğin dış zarfı niteliğinde ve ayrıca Çamlıca, Karabiga ve Karadağ gibi bölgenin diğer metamorfik masiflerinde yüzeyleyen bu metamorfik kayaların litolojik, stratigrafik ve yapısal olarak büyük benzerlikler göstermesinin yanı sıra U-Pb zirkon yaşları da bunların birbirleriyle benzer olduklarını göstermektedir. $\mathrm{U}-\mathrm{Pb}$ zirkon yaş tayini çalışmalarından elde edilen sonuçlara göre Kalabak Birliği’ne ait metasedimanter kayaların protolitlerinin maksimum çökelme yaşları 557-582 My aralığındadır. Bunlarla birincil ilişkili metabazitlerden elde edilen protolit kristalizasyon yaşı ise 577 My'dır. Ayrıca bu metasedimanter kayalar içerisinde tektonik dilimler halinde bulunan eklojitlerin protolit kristalizasyon yaşı da 565 My'dır. Benzer protolit yaşlarına ek olarak, yaklaşık 300-340 My civarında gerçekleşmiş bir tektonotermal olayın izi de tüm örnekler için ortak bir jeolojik geçmişi ifade etmesi açısından önemlidir.

Kalabak Birliği'ne ait metavolkanik kayaların oluşum ortamı ve yaşı birbirleriyle tutarlı ve uyumlu jeotektonik ortamları temsil etmektedir. Bugünkü konumuyla görülür en altta yer alan Dedetepe Formasyonu bir dalma-batma melanjını, Sazak Formasyonu bir aktif kıta kenarını ve Torasan Formasyonu ise bunlarla yaşıt bir çökel istifi temsil etmektedir. Bu jeotektonik ortamlar geç Prekambriyen-erken Paleozoyik döneminde Proto-Tetis okyanusu tabanındaki litosferik levhanın güneye, Gondwanaland kıtasının altına dalması esnasında oluşmuştur. Sakarya Zonu'nun bu en yaşlı kayaları, daha genç dönemlerde, bir arada bulundukları kayalarla birlikte, tekrarlayan deformasyonlardan etkilenmişler ve bugünkü konumlarını kazanmışlardır.

Anahtar Kelimeler: Biga Yarımadası, Gondwanaland aktif kıta kenarı, Pan-Afrikan Orojenezi, Sakarya Zonu 


\begin{abstract}
The pre-Jurassic metamorphic rocks of the Biga Peninsula can be evaluated as three main tectonostratigraphic units, which show significant differences from each other in terms of degree of metamorphism, deformation characteristics and tectonic settings. These are: 1) Kazdăg Unit, 2) Kalabak Unit, and 3) Karakaya Unit. The Kazdağ Unit forms the high-grade metamorphic core rocks of the Kazdağ Massif on the visible base of the Biga Peninsula. The Kalabak Unit and the Karakaya Unit are located on this high-grade metamorphic basement as composite tectonic slices and form the lower-grade metamorphic outer envelopes.
\end{abstract}

The Kalabak Unit, which is the main subject of this paper, consists of the Dedetepe Formation, the Sazak Formation, the Torasan Formation, and Devonian Çamlık metagranodiorite, which cuts all these units. In addition to lithological, stratigraphic and structural similarities of these metamorphic rocks, which are the outer envelope of the metamorphic core in the Kazdağ Massif and also outcrop in other metamorphic massifs of the region such as Çamlica, Karabiga and Karadağ, their U-Pb zircon ages also show that they can be correlated with each other. According to the results obtained from U-Pb zircon dating, the maximum sedimentation ages of the protoliths for the metasedimentary rocks of the Kalabak Unit are in the range of 557-582 Ma. The crystallization age of the protolith for the metabasites, which has primary relationship to these metasedimentary rocks, is $577 \mathrm{Ma}$. In addition, protolith crystallization age of the eclogites, which are tectonic slices in these metasedimentary rocks, is $565 \mathrm{Ma}$. In addition to similar protolith ages, the fingerprint of a tectonothermal event at about 300-340 Ma is important in terms of expressing a common geological history for all samples.

Formation environment and age of the metavolcanic rocks of the Kalabak Unit represent consistent and significant geotectonic environments. The Dedetepe Formation, which is at the bottom, represents a subduction mélange, the Sazak Formation represents an active continental margin and the Torasan Formation represents a coeval sedimentary sequence. These geotectonic environments developed during the late Precambrian-early Paleozoic period while the Proto-Tethys oceanic crust subducted to the south, under the Gondwanaland continent. These oldest rocks of the Sakarya Zone, together with the rocks they were spatially associated with during younger periods, were affected by repetitive deformations which resulted in their present position.

Keywords: Biga Peninsula, Gondwanaland active continental margin, Pan-African Orogeny, Sakarya Zone

\section{GÍRIŞ}

Biga Yarımadası; Sakarya Kıtası (Şengör ve Y1lmaz, 1981; Şengör vd., 2019), Sakarya Zonu (Okay vd., 1991), Sakarya Kompozit Kuşağ1 (Göncüoğlu, 2010) gibi adlarla anılan Alpin tektonik kuşağın karma temel kayalarının en iyi görüldüğü alanlardandır. Biga Yarımadası'ndaki metamorfik kayaları konu edinen pek çok çalışma bulunmakla beraber (Beccaletto 2004; Beccaletto ve Jenny 2004; Yaltırak ve Okay 2004; Aygül vd., 2012; Aysal vd., 2012a ve b; Tunç vd., 2012), yarımadanın tümünü kapsayan iki önemli çalışma Okay vd. (1991) ve Duru vd. (2012) tarafindan gerçekleştirilmiştir. Bu çalışmalara göre; Biga Yarımadası'nın jeolojisi genel hatlarıyla Kazdağ, Karadağ, Çamlıca, Karabiga masiflerinde mostra veren metamorfik temel kayaları ile bunları örten çökel ve volkanik kayalarla temsil edilmektedir (Şekil 1). Yarımadanın kuzey-kuzeybatı kesimlerindeki metamorfik ve ofiyolitik kayalar "Ezine Zonu", güneydeki Kazdağ Masifi ve onun örtüsü durumundaki kayalar ise "Sakarya Zonu" olarak adlandırılmıştır. İkisi arasında yer alan ve başlica bloklu karmaşı topluluklar içeren bir kesim ise "Ayvacık-Karabiga Zonu" olarak adlandırılmıştır. Daha sonra Ezine Zonu da, aradaki bir ofiyolit zonu (Denizgören ofiyoliti) ile kendi içinde batıda "Karadağ İstifi" ve doğuda "Çamlıca metamorfikleri” olarak ayrıca iki zona ayrılmıştır (Okay vd., 1991; Beccaletto ve Jenny, 2004). Bu haliyle birbirinden farklı kitasal temeller ve aralarındaki kenet (ofiyolit/mélanj) zonlarını temsil ettiği düşünülen bu detaylı sınıflandırma her bir "zon"daki istifsel ve yapisal niteliklerin birbirinden bağımsız değerlendirilmesine neden olmuştur. $\mathrm{Bu}$ zon ayırd1, Duru vd. (2012) tarafindan yapılan ayrıntılı haritama çalışmalarında da yansımasını bulmuştur. Nitekim 
"Sakarya Zonu" olarak tanımlanan güney zonda metamorfik kayalarda yapılan ayrintılı kayastratigrafi ayırdına dayalı haritalama, kuzeyde "Ezine Zonu" olarak tanımlanan kesimde yapılan ayırtlarla karșılaștırılmamış, sonuçta adeta bir güney kuşak ve kuzey kuşak metamorfik zonları ile bunlar arasındaki bir "mélanj” kuşağından oluşan harita deseni ortaya çıkmıştır (Duru vd., 2012; MTA, 2012).
Bölgede bugüne kadar yapılan tüm çalışmaların üzerine, yapmış olduğumuz yeniden haritalama ve ayrıntılı saha çalışmaları; yukarıda sözü edilen “zon”ların stratigrafik olarak birbirleriyle önemli oranda karșılaștırılabilirliğini ve birbirlerinden de kenet kușaklarıyla ayrılmadığını, tektonostratigrafik bakımdan birbirlerinin devamı niteliğinde olduğunu ortaya koymuştur.

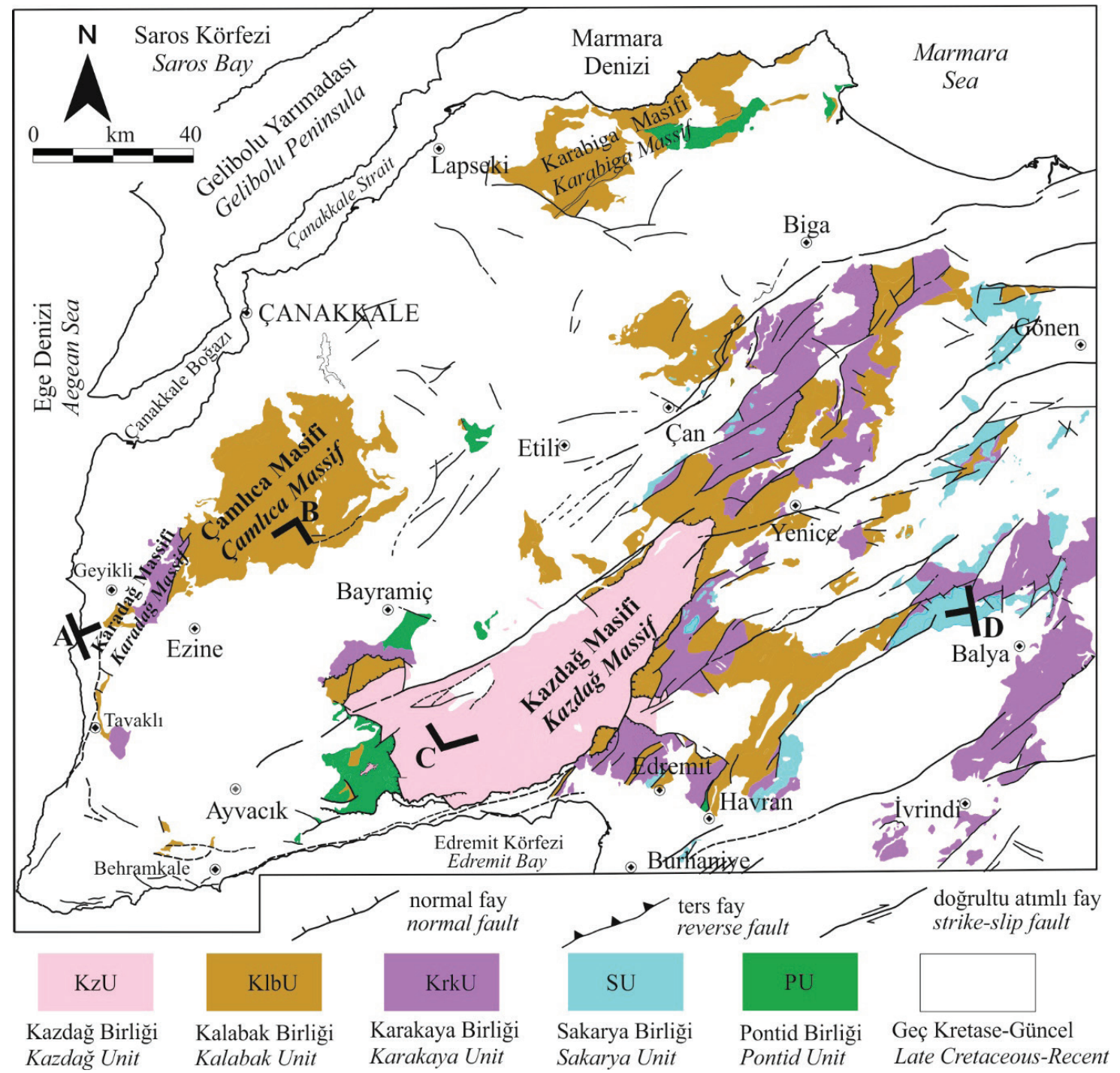

Şekil 1. Biga Yarımadası'ndaki tektonostratigrafik birliklerinin dağılımını gösterir jeoloji haritası (Temel harita Duru vd., 2012'den alınmış, kendi verilerimizle yenilenmiş̦ir).

Figure 1. Geological map showing the tectonostratigraphic units in the Biga Peninsula (Base map modified after Duru et al., (2012) with our data). 


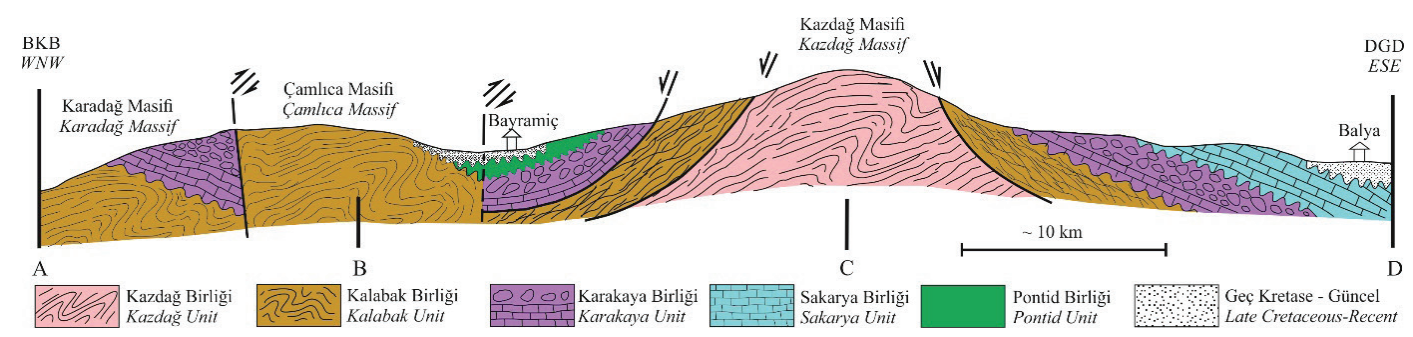

Şekil 2. Biga Yarımadası'ndaki metamorfik birliklerin tektonostratigrafik ilişkilerini gösterir genelleştirilmiş kompozit jeoloji enine kesiti. (Kesit, bir düzlem üzerinde ilişkileri gösterebilmek amacıyla sadeleştirilerek genelleştirilmiş olup bu nedenle Şekil 1'deki jeolojik harita üzerindeki kesit güzergâhındaki bazı ayrıntıları göstermemektedir).

Figure 2. Composite geological cross-section, showing the tectonostratigraphic relationships of the metamorphic units in the Biga Peninsula. (The cross-section is simplified and generalized in order to show the relations on a plane and therefore does not show some details of the section line on the geological map in Figure 1).

Bu makalede, söz konusu araştırmalarda elde edilen veri ve bunların metamorfik temele ait bazı sonuçları sunulmaktadır. Burada sunulan analitik veriler TÜBİTAK 110Y281 ve 115Y214 No'lu araştırma projesi sonuç raporlarında (Yiğitbaş vd., 2014; 2018a) bulunmaktadır. Makalenin hacmine sığamayacak büyüklükteki bu analitik verilere şu adreslerden ulaşılabilinir;

https://rdizin.gov.tr/publication/show/pdf/project/TVRnNU16azU= https://trdizin.gov.tr/publication/show/pdf/project/TVRnNU5ESXk=

Biga Yarımadası'nda tektonostratigrafik bakımdan istifin yapısal en alt düzeyleri Kazdağ Masifi'nde yüzeyler (Şekil 1 ve 2). Kazdağ Masifi, Biga Yarımadası'nın en güney kesiminde Edremit Körfezi kıyısından itibaren kuzeydoğu yönünde uzanmakta ve kuzeydoğuya dalımlı bir antiform oluşturmaktadır. $\mathrm{Bu}$ antiformun çekirdeğindeki ileri derecede metamorfik temel kayaları tipik bir gnays domu görünümündedir. $\mathrm{Bu}$ ileri derecede metamorfik çekirdek, daha zayıf dereceli metamorfik Geç Prekambriyen-Erken Paleozoyik birlik tarafından tektonik dokanakla örtülür (Tunç vd., 2012; Yiğitbaş vd., 2014). Kalabak Birliği olarak adlandırılan bu metamorfik kayalar da metamorfizma nitelikleri daha da düşük olan Permiyen ve/veya Triyas yaşlı Karakaya Birliği tarafindan açısal uyumsuzlukla örtülür (Şekil 1 ve 2).
Sadece metamorfizma derecesi ve deformasyon nitelikleri bakımından bile birbirlerinden ayrilabilen bu tektonostratigrafik birlikler bu araştırmanın sonunda üç birlik adı altında toplanmıştır. 1) Kazdağ Masifi’nin amfibolit-granulit fasiyesinde metamorfik çekirdeğini oluşturan ve bölgenin görülür tektonostratigrafik temelini teşkil eden Kazdă Birliği, 2) Devoniyen yaşlı metagranodiyoritlerle kesilen, metaofiyolit dilim ve mercekleri içeren, yeşil-şist fasiyesinde metamorfizmaya uğramış bir metavolkanik-metasedimenter istif Kalabak Birliği, 3) Tabanında Permiyen yaşlı bir karbonat istifi bulunan ve bunun üzerinde Permiyen blokları da içeren, düzenli ve karmaşık topluluklardan oluşan, çok değişken litolojik ve yapısal karaktere sahip Permiyen-Triyas yaşlı kalın volkanik-çökel

\section{Karakaya Birliği.}

$\mathrm{Bu}$ makalede tarafımızdan (Yiğitbaş vd., 2018a ve b) Kalabak Birliği olarak tanımlanan tektonik birlik üzerinde durulacak, bu birliği oluşturan kayaların özellikleri ve bunların bölge jeolojik evrimi üzerindeki anlam ve önemleri tartış1lacaktır.

\section{TEKTONOSTRATIGRAFI}

\section{Kalabak Birliği}

Kalabak Birliği bu çalışmada kullanıldığı anlam ve konumuna en yakın biçimde ilk kez Duru vd. (2012) 
tarafindan Kalabak Grubu olarak Sazak ve Torasan formasyonları ile Çamlık metagranodiyoritini kapsayacak şekilde tanıtılmıştır. Bu makalede ise; a) Okay vd. (1991) tarafindan Ezine Zonu içinde tanıtılan ve Üst Kretase (?) yaşı verilen Çamlıca Grubu ve eşdeğerleri ile b) Duru vd. (2012)'nin Geyikli Formasyonu da Kalabak Birliği içinde yer alan birimlerle karşılaştırılarak değerlendirilmiştir. Bunun yanı sıra tektonik evrim sürecinde yaşamış oldukları ortaklık nedeniyle bölgedeki bazı metaofiyolitik kayalar da Kalabak Birliği içine dahil edilmiştir. Bu durumda; Biga Yarımadası'nda ilk kez bu araştırmada bir "tektonik birlik" olarak adlanarak tanıtılan Kalabak Birliği; 1) Dedetepe Formasyonu, 2) Sazak Formasyonu, 3) Torasan Formasyonu ve 4)Çamlık metagranodiyoriti olmak üzere dört jeolojik alt birimden oluşmaktadır. Aşağıda bu birimler ayrı ayrı tanıtılacaktır.

\section{Dedetepe Formasyonu}

Birim esas itibariyle metaofiyolit-mavişisteklojit dilim ve mercekleri ile bunların matriksini oluşturan metapelitik şist, fillat, gnays, amfibolit ve daha az oranda mermerlerden oluşmaktadır. Tüm bu kayaçlar ileri derecede sünek-yarı kırılgan makaslamaya uğramış ve dilimlenmiş bir karmaşı görünümündedir.

Birimin en yaygın kayaçları tipik olarak gümüş gri, kahverengi, kirli beyaz, yeşilimsi kahve renkli, iyi foliasyon ve lineasyon gösteren muskovit-kuvars şist, granat-mika şist, granatepidot şist, mermer ve kalkşist ardalanmasıyla temsil edilmektedir. Mercekler şeklinde gözlenen mermerlerin kalınlıkları genellikle 50-250 m arasında değişmektedir. Şistler; kuvars + muskovit + albit + granat + aktinolit + epidot + klorit \pm zirkon \pm sfen parajenezi içermektedir. Buradaki albit + epidot parajenezi orta basınç/orta sicaklık yeşil-şist fasiyesini temsil etmektedir. Albit + epidot parajenezine granatın eklenmesiyle granat zonu koşullarının da geliştiği anlaşılmaktadır.
Dedetepe Formasyonu, Çamlıca masifinde Kalabak Birliği'nin en alt tektonostratigrafik birimini oluşturur. Birimin tabanı inceleme alanı ve yakın çevresinde görülmemektedir. Çamlıca masifinde Dedetepe Formasyonu üzerinde Sazak Formasyonu tektonik dokanakla yer almaktadır (Şekil 3 ve 4). Dokanak yer yer on metreyi aşan genişlikte bir makaslama zonudur. $\mathrm{Bu}$ zon içerisinde Sazak Formasyonu'nun metavolkanik kayaları ile Dedetepe Formasyonu'nun metabazit ve metapelitik kayaları birbirleriyle iç içe bir konum sergiler ve foliasyon düzlemlerine paralel uzanan mercek ve kamalar şeklinde birbiri içinde yer alır. Dokanak zonu daha sonraki kırılgan deformasyonlardan etkilenmiş olmakla birlikte kuzeye eğimli sünek-yarı kırılgan bir makaslama zonu niteliğindedir. Üzerinde bulunan Sazak ve Torasan formasyonlarına nazaran ileri derecede deformasyon geçirmiş, içerisinde eklojit, mavi şist metagabro-amfibolit tektonik mercekleri bulunan Dedetepe Formasyonu heterojen yapılı bir metamorfik melanj görünümündedir.

Çamlıca masifinde Dedetepe Formasyonu'ndan iki adet mikaşist (11-181 ve 11-184) ve bir adet eklojit örneği (11-248) Laser Ablation Inductively Coupled Plasma Mass Spectrometry (LA-ICP-MS) U-Pb zirkon yöntemiyle tarihlendirilmiştir (Şekil 5A ve 5B; Tunç vd., 2012; Yiğitbaş vd., 2014). Mikaşist örneklerinden elde edilen sonuçlar üç ana jeolojik olay1 işaret etmektedir. Diskordiya çizgisi, konkordiya eğrisini iki noktada kesmektedir. Bunlardan üst kesişim noktası (c. 567 My) protolitin çökelimi için bir maksimum yaşı işaret etmektedir. Alt kesişim noktası (c. $28 \mathrm{My}$ ) ise Biga Yarımadası'nda granitoyid magmatizmasının eşlik ettiği geç Alpin orojenezi ile ilgili en son kurşun kaybını göstermektedir. Öte yandan daha önceki bir diğer kurşun kaybı dönemi de yaklaşık 300340 My dolayında olmuştur (Şekil 5A). Dedetepe Formasyonu mikaşistlerinde kurşun kaybından etkilenmemiş en genç zirkon popülasyonu kullanılarak elde edilen protolitin maksimum

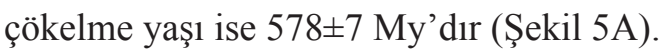




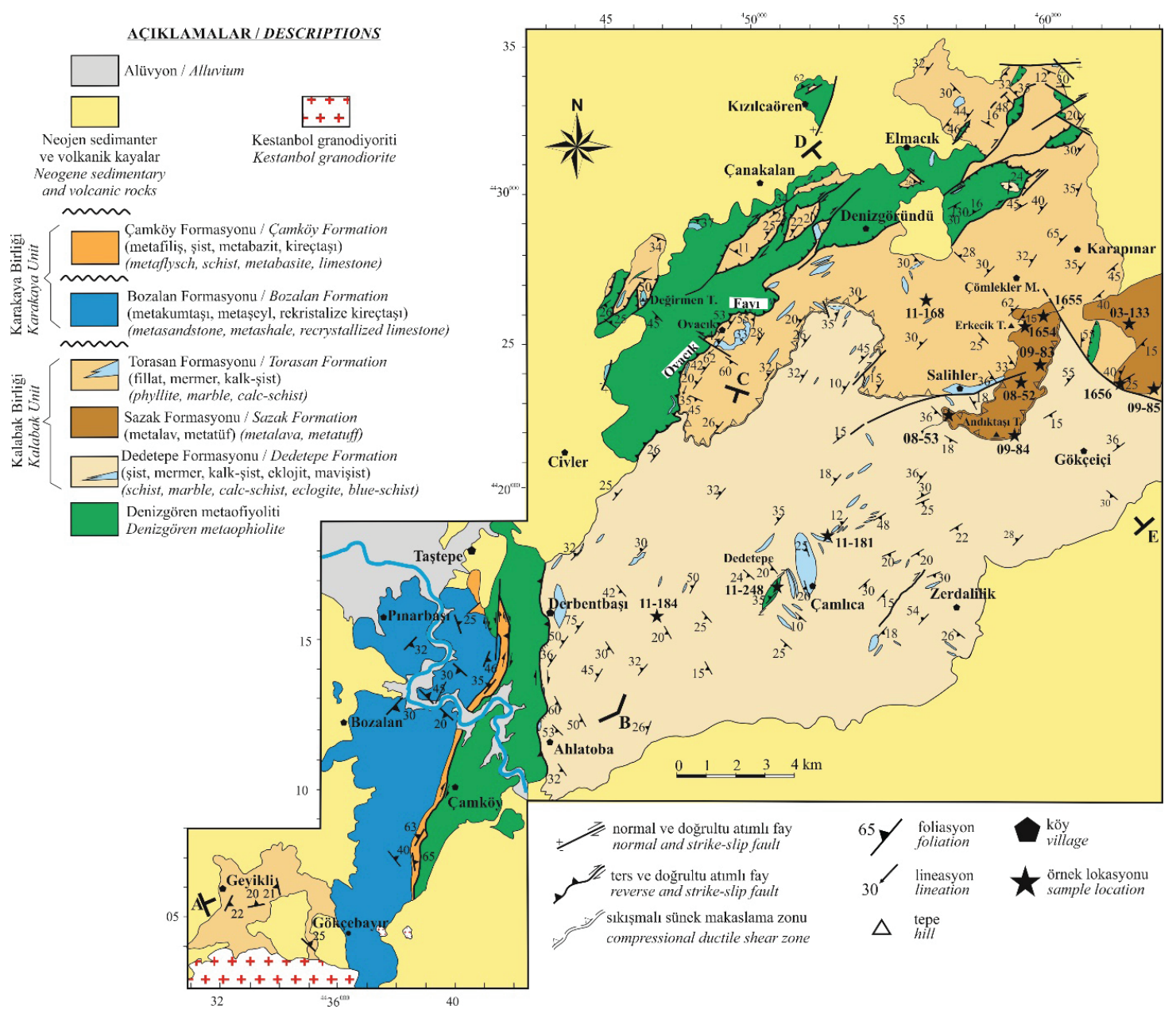

Şekil 3. Çamlıca ve Karadağ masiflerinin jeoloji haritası. Harita Okay vd. (1990), Beccaletto (2004), Şengün (2005), Duru vd. (2012)'den yararlanılarak kendi saha gözlemlerimizle hazırlanmıştır.

Figure 3. Geological map of Çamlica and Karadă massifs. The map was modified after Okay et al. (1990); Beccaletto (2004); Şengün (2005) and Duru et al. (2012) by using our own field observations.

Eklojit örneğinden elde edilen sonuçlar da mikaşist örneklerinde olduğu gibi üç ana jeolojik olayı işaret etmektedir. Diskordiya çizgisi, konkordiya eğrisini iki noktada kesmektedir. Bunlardanüstkesişimnoktası (c. $591 \mathrm{My}$ ) protolitin kristalizasyon yaşını gösterirken, alt kesişim noktası (c. $20 \mathrm{My}$ ) ise geç Alpin orojenezi ile ilgili en son kurşun kaybı olarak değerlendirilmiştir. Üçüncü önemli jeolojik olay ise yaklaşı 340 My dolayında olmuştur (Şekil 5B). Eklojitlerde kurşun kaybından etkilenmemiş en genç zirkon popülasyonu kullanılarak elde edilen protolitin kristalizasyon yaşı ise $565 \pm 9$ My'dır. Bu yaş
Dedetepe Formasyonu eklojitlerinin oluşum yaş1 olarak, mikaşistlerdeki $578 \pm 7$ My ise protolitin maksimum çökelme yaşı olarak değerlendirilmiştir ve birbirleriyle uyumludur. Böylece geç Prekambriyen döneminde gelişmiş olan eklojitler, aynı dönemde bölgede gelişmekte olan bir yı̆̆ışım karmaşı̆̆ı içerisine yerleşmiş olmalıdır. Yaklaşık 340 milyon yıla karşıllk gelen kurşun kaybı her iki kaya grubunda da belirgin şekilde görülmektedir. Bu durum; geç Prekambriyen'de biraraya gelmiş olan farklı kökendeki bu kayaların Variskan (?) tektonomagmatik olaylardan birlikte etkilendiklerini göstermektedir (Şekil 5A ve 5B). 


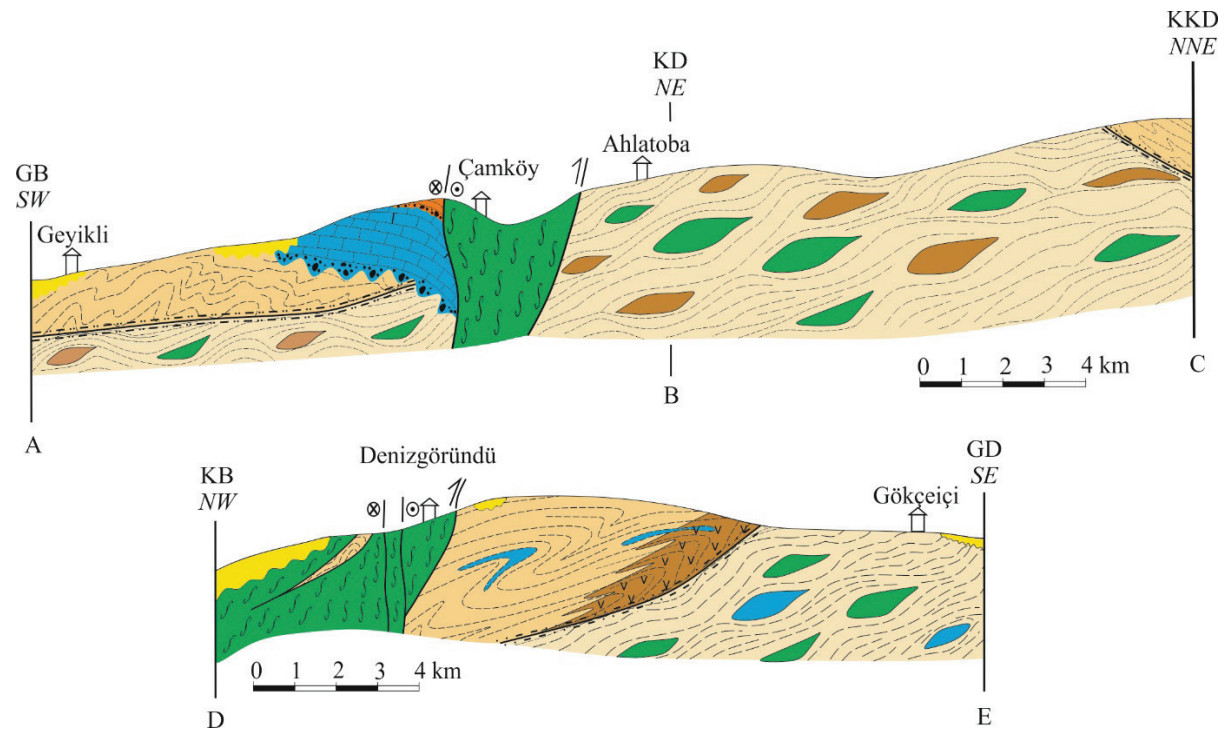

Şekil 4. Çamlıca ve Karadağ masiflerinde Kalabak Birliği'ne ait kayaçların ilişkilerini gösterir jeoloji enine kesiti. Açıklamalar için Şekil 3'e bakınız.

Figure 4. Geological cross-section, showing the relationships of the Kalabak Unit rocks in Çamlica and Karadağ massifs. See Figure 3 for legend.

\section{Sazak Formasyonu}

Sazak Formasyonu, ayrışmış yüzeyde kahverengimsi sarı ve haki, taze kırık yüzeyde ise yeşilimsi kahve renklerde başlıca metatüf ve metavolkanik kayalardan oluşmaktadır. Metavolkaniklastik ve mermer arakatmanları da içerir. Birimin Biga Yarımadası'ndaki yüzeyleme dağılımı Torasan Formasyonu'nun dağılımı ile mekansal birliktelik göstermektedir. Sazak ve Torasan formasyonları çoğu zaman birbirleriyle birincil stratigrafik dokanaklı olarak, Kazdağ antiformunun KD uzanımı ve yapının GD kanadı boyunca birlikte yüzeylemektedir (Duru vd., 2012). Tipk1 Torasan Formasyonu gibi Sazak Formasyonu'nun da Kazdağ antiformuna nazaran KB kanatta herhangi bir dağılımı bugüne kadar haritalanmış değildir. Oysa 110Y281 ve 115 Y214 No'lu TUBİTAK projeleri kapsamında yapmış olduğumuz ayrıntılı saha çalışmalarında (Yiğitbaş vd., 2014; 2018a), Çamlıca Grubu (Okay vd., 1991) olarak haritalanan birimin bazı seviyelerinin Sazak Formasyonu ile litolojik ve jeokronolojik niteliklerinin bire bir benzerlik gösterdiği tespit edilmiştir.
Çamlıca masifinde Sazak Formasyonu makroskobik olarak düzensiz kırıklı, kötü yapraklanmalı ve masif bir yap1 sunmaktadir. Birimde metamorfizma derecesine bağlı olarak volkanik kökeni yansıtan kalıntı porfirik dokusal özellikler gözlenmektedir (Şekil 6). Kayada foliasyon diğer birimlere nazaran daha zayıf gelişmiştir. Genellikle mat ve soluk görünümlü olan bu metavolkanik kayalar, epidotça zengin kesimlerde ve alterasyondan korundukları alanlarda parlak fistık yeşili renkte görünmektedir. Birimin yüzeylemeleri KD-GB yönünde uzanım göstermekte olup Torasan Formasyonu'nun metapelitik birimleriyle uyumlu yapısal ve stratigrafik ilişkiler sunmaktadır. Bu ilişkinin en iyi görüldüğü yerlerden biri Salihler-Kuşçayırı yolunun 2,5. km' sinden (UTM 35S 0458950 E-4424512 N) kuzeye Çömlekler mahallesi istikametine sapan yolun Erkecik tepe dolayından geçtiği kesimlerdir. Yol kavşağından Erkecik tepeye kadar metavolkanik-metatüf kayaları egemen olarak yüzeyler. Ancak Erkecik tepeyi kuzeye doğru geçtikten sonraki ilk $1 \mathrm{~km}$ içinde, yolun iki tarafindaki araziye yüründüğünde metavolkanik kayaların yanal ve düşey yönde metapelit ve mermerlere geçtiği görülmektedir. 

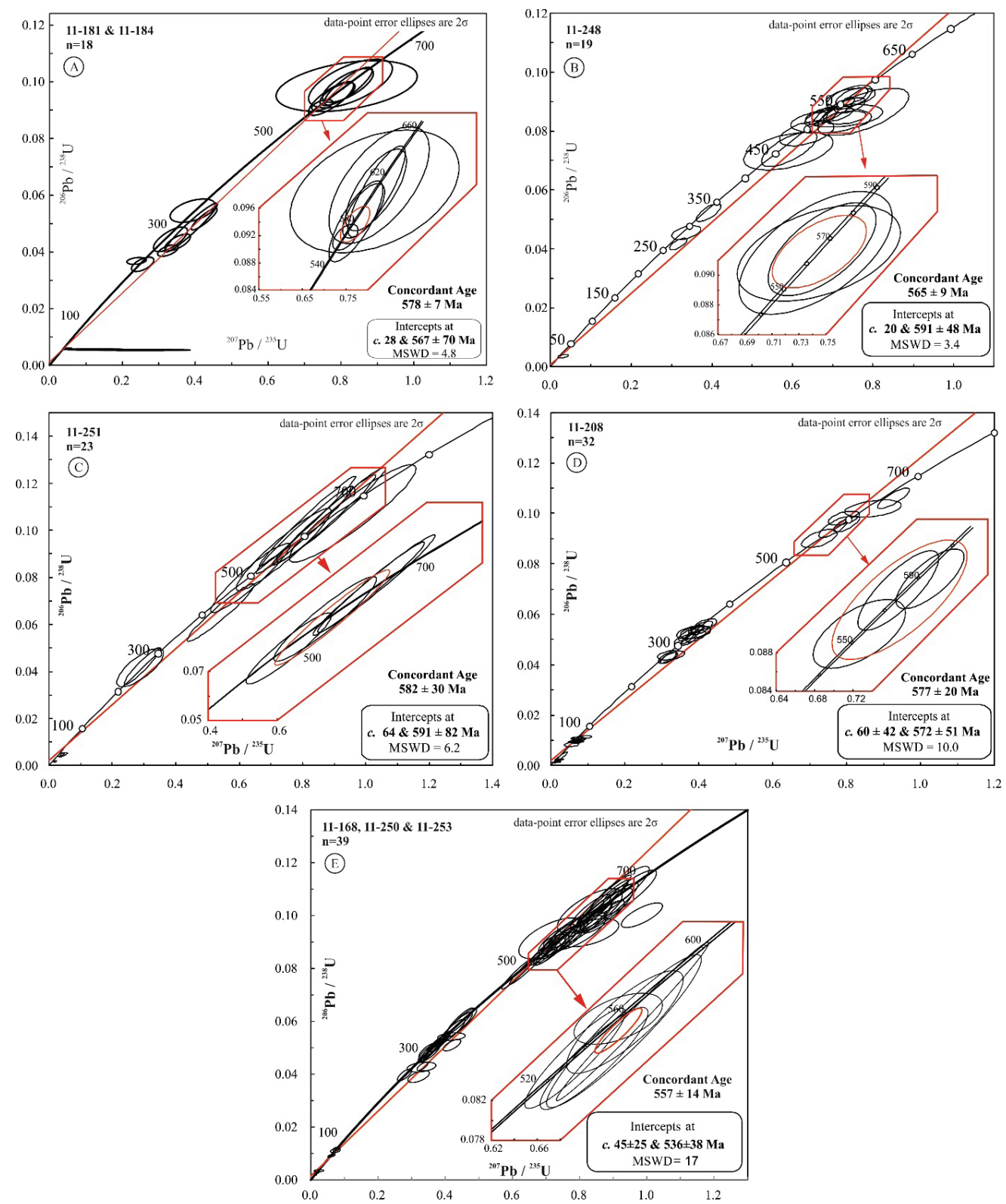

Şekil 5. Kalabak Birliği'ne ait birimlerden elde edilen U-Pb zirkon yaşları. A) Dedetepe Formasyonu mikaşist örnekleri, B) Dedetepe Formasyonu içerisindeki eklojit örneği, C) Karabiga masifindeki Sazak Formasyonu mikaşist örneği, D) Karabiga masifindeki Sazak Formasyonu metavolkanik örneği E) Çamlıca masifindeki Torasan Formasyonu mikaşist örnekleri. Tüm örneklere ait U-Pb zirkon konkordiya diyagramları birbirine benzer dağılım göstermektedir. Bu örneklerde iki önemli tektonotermal olayın (episodik kurşun kaybı) izleri bulunmaktadır. Bunlardan biri yaklaşık 340-300 My (Variskan? veya Paleo-Tetis) diğeri ise yaklaşık 65-20 My (Alpin-geç Alpin)'dır.

Figure 5. U-Pb zircon ages from the Kalabak Unit. A) micaschist samples from the Dedetepe Formation, B) eclogite sample in the Dedetepe Formation, $\boldsymbol{C}$ ) micaschist sample from the Sazak Formation in the Karabiga massif, D) metavolcanic sample from the Sazak Formation in the Karabiga massif, E) micaschist samples from the Torasan Formation in the Çamlica massif. The U-Pb zircon concordia diagrams from these samples show remarkably similar patterns. There are two major complex tectonothermal overprints (episodic lead loss events), at c. 340-300 Ma (Variscan? or Paleo-Tethyan) and c. 65-20 Ma (Alpine and late Alpine?), respectively. 


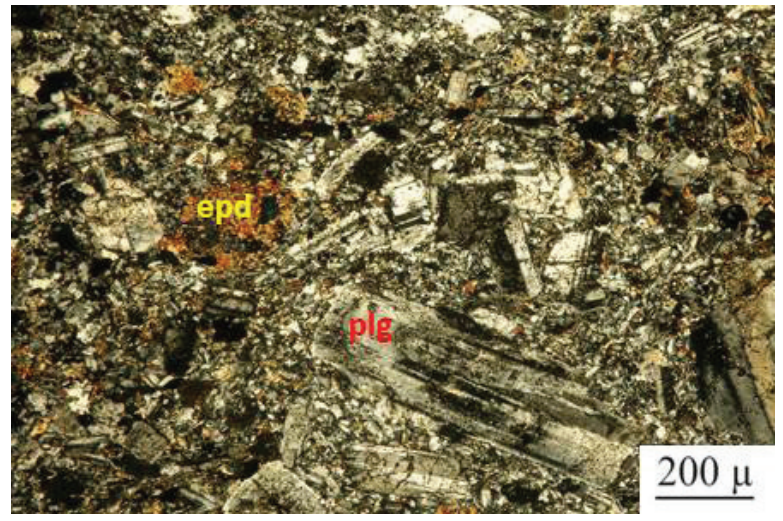

Şekil 6. Çamlıca masifindeki Sazak Formasyonu'na ait metavolkanik kayalardaki kalıntı volkanik dokuyu gösterir mikrofoto (epd: epidot, plg: plajioklaz)

Figure 6. Microphoto showing the relict volcanic texture in a metavolcanic rock from the Sazak Formation in the Çamlıca massif (epd: epidote, plg: plagioclase)

Çamlıca masifinde Sazak Formasyonu'nun en yaygın litolojisini metalav ve metatüfler oluşturmaktadır. Metalavlardan alınan örneklerden hazırlanan ince kesitlerin mikroskop altında incelenmeleri sonucunda bunların genel mineral bileşimi albit + epidot + aktinolit + plajiyoklas + kuvars + klorit + kalsit \pm ortoklas \pm sfen \pm zirkon olarak saptanmıştır. Düşük dereceli metamorfizmaya rağmen bu kayalarda mikroskop altında kalıntı volkanik doku yer yer gözlenmektedir (Şekil 6). Kalıntı volkanik doku içerisinde yaygın plajiyoklas fenokristalleri ve bunları saran yeniden kristallenme geçirmiş mikrokristalen bir matriks bulunmaktadır. Çamlıca masifinde Sazak Formasyonu'nun metavolkanik kayalarından alınan örneklerden bazılarında (örn. 1654 ve 1656 nolu örnekler) nadiren de olsa küçük kristaller halinde özşekilsiz ve dalgalı sönme gösteren kuvars ve düşük röliyefli, alterasyona rağmen halen tanınabilen ortoklas minerali görülmektedir. Nitekim bu alandan alınan metavolkanik kaya örneklerinin jeokimyasal nitelikleri de bunların bazalttan dasit/ riyodasite değiştiğini göstermektedir (Şekil 8C).
Çamlica masifinde Sazak Formasyonu Dedetepe Formasyonu üzerinde tektonik dokanakla yer almaktadır (Şekil 3).

Karabiga masifinde Sazak Formasyonu Ayıtdere fayının güney blokunda geniş bir șekilde yüzeylemektedir(Şekil 7). Bu alanda metavolkanik kayalar ayrışmış yüzeyde kahverengimsi sarı ve haki, taze yüzeyde ise yeşil renkli, ince-orta taneli ve kötü foliasyonlu olup bazı alanlarda morumsu gri renkte, ince taneli ve iyi foliasyonlu fillatlar ve mermerlerle ardalanmaktadır. Birim içerisinde çok sayıda makaslama düzlemleri ve milonit zonları gelişmiştir. Metavolkanik kayalar yer yer bu milonitik matriks içinde yüzen budinler halinde görülmektedir. Bu nedenle de birimin bazı mostraları önceki çalışmalarda "Çetmi melanjı" içinde gösterilmiştir (Okay vd., 1990; Beccaletto, 2004; Aygül vd., 2012).

Petrografik incelemeler sonucunda metavolkaniklerin genel mineral bileşimleri albit + epidot + plajiyoklas + tremolit/aktinolit + zoisit + klorit \pm kuvars \pm sfen \pm opak olarak saptanmıştır. $\mathrm{Bu}$ parajenez ve dokusal nitelikleri birimin yeşilşist fasiyesinde metamorfizmaya uğradığını göstermektedir.

Karabiga masifinde Sazak Formasyonu'nun üzerine uyumsuz bir dokanakla Alt Kretase yaşı 1 Çetmi Grubu gelmektedir (Şekil 7; Yiğitbaş vd., 2009 a; b; 2014; Tunç vd., 2012).

Sazak Formasyonu'na ait metavolkanik kayalar kondrite göre normalize edilmiş nadir toprak elementleri çoklu element diyagramında değerlendirildiğinde bu kayaçların ağır nadir toprak elementlerine (HREE) oranla, hafif nadir toprak elementlerince (LREE) zenginleştikleri görülür (Şekil 8A). (La/Y)cn oranı 3,47 ile 8,63 arasındadır. Bu da hafif nadir toprak elementlerince zenginleşmeyi ifade etmektedir. Eu anomalisi kayaçlarda başlıca plajiyoklas ile kontrol edilir. $\mathrm{Bu}$ yüzden kristallenme veya kayacın kısmi ergimesiyle ergiyikten plajiyoklasın ayrılması, sonuçta ergiyik içinde negatif $\mathrm{Eu}$ anomalisine 
neden olur (Rollinson, 1993). İncelenen örneklerde Eu anomalileri bölgeden bölgeye ve örnekten örneğe değişkenlik göstermektedir. Karabiga masifinden alınan örneklerde $\mathrm{Eu} / \mathrm{Eu}^{*}$ oranı 0,96-1,01 arasında iken Çamlıca masifinden alınan örneklerde $\mathrm{Eu} / \mathrm{Eu}^{*}$ oran1 0,64-0,82 arasında değişmektedir. Bu genel desen içinde; Çamlıca ve Karabiga masiflerindeki örneklerde kondrite normalize REE desenlerinde Eu dışında bir paralellik görülür. Eu açısından, başka bir ifadeyle plajiyoklas farklılaşması bakımından bir gruplaşma göze çarpar. Çamlıca masifindeki metavolkanik kayalarda zayıf da olsa plajiyoklas ayrımlaşması gözlenirken 11-207 ve 11-205 nolu Karabiga masifindeki örneklerde bu durum söz konusu değildir.

Çamlıca ve Karabiga masiflerinden alınmış olan metavolkanik kaya örneklerinden elde edilen jeokimyasal veri MORB'a göre normalize edilmiş çoklu element diyagramlarında değerlendirilmiştir (Şekil 8B). Bukayaların tamamında diyagramın sağ tarafindaki en az uyumsuz elementler (compatible elements) ve HFS (High-Field Strength) elementler MORB'a uyumlu bir desene sahipken, uyumsuz elementler (incompatible) ve LIL (Large Ion Lithophile) elementler bakımından belirgin bir zenginleşme görülmektedir. MORB'a göre normalize edilmiş çoklu element diyagramlarında tüm örneklerde ortak olan bu özellik yanı sira Çamlıca masifinden alınan örneklerde negatif $\mathrm{Nb}$, $\mathrm{Zr}$, Hf ve Ti anomalileri dikkati çekmektedir. Nadir toprak elementlerindeki fraksiyonel farklılaşmayla birlikte $\mathrm{Nb}$, Hf ve $\mathrm{Zr}$ elementlerindeki negatif anomaliler yakınsayan levha kenarı tektonik ortamını işaret etmektedir (Wilson, 1989; Gill, 2010; Yiğitbaş vd., 2004 ve oradaki referanslar). Karabiga masifinden alınan 11-207 ve 11-205 nolu örnekler ise MORB'a göre normalize edilmiş çoklu element diyagramında diğerlerinden farklı olarak $\mathrm{Nb}, \mathrm{Hf}, \mathrm{Zr}$ ve Ti negatif anomalileri göstermezler. $\mathrm{Bu}$ örneklerde de HREE'ler ve uyumlu elementler MORB değerlerine yakın; LREE'ler, uyumsuz LIL elementler ve uyumsuz elementler bakımından 8 ila 80 kat zenginleşme görülmektedir (Şekil 8B). $\mathrm{Bu}$ nitelikler bugün Atlantik’te Azor ve Pasifik tabanında bulunan Kohala alkali bazaltlarında olduğu gibi; levha içi okyanusal ada bazaltları için karekteristiktir (Wilson, 1989; Gill, 2010 ve bunlardaki referanslar).

Çamlıca masifinden alınan subalkalen nitelikli metavolkanit örneklerinde $\mathrm{SiO}_{2}$ 'ye karşı $\mathrm{Zr} / \mathrm{TiO}_{2}$ diyagramında (Winchester ve Floyd, 1977) tıpk1 volkanik yay bazaltlarında olduğu gibi BADR (Bazalt-Andezit-Dasit-Riyolit) fraksiyonlaşması görülmektedir (Şekil 8C). Winchester ve Floyd (1977)'nin $\mathrm{Zr} / \mathrm{TiO}_{2}$ 'a karşı $\mathrm{Nb} / \mathrm{Y}$ diyagramında ise Çamlıca masifinden alınan metavolkanit örnekleri subalkalen bazalt ile andezit alanında yer alırken Karabiga masifinden alınan örnekler bunlardan farklı olarak alkali bazalt alanında yer almaktadır (Şekil 8D).

Sazak Formasyonu'nun Çamlıca ve Karabiga masiflerindeki yüzleklerinden alınan metavolkanit örnekleri tektonik ayrım diyagramlarında da değerlendirilmişlerdir (Şekil 8E; Pearce, 1983 ve Wood, 1980). Bu amaçla kullanılan diyagramlar mümkün olduğunca alterasyon ve metamorfizma esnasinda hareketli olmayan elementlerden seçilmiştir. Bilindiği gibi $\mathrm{Na}, \mathrm{K}, \mathrm{Ca}, \mathrm{Ba}, \mathrm{Rb}, \mathrm{Sr}$ ve LREE'ler bu anlamda hareketli elementlerdir ve tektonomagmatik ayrım amaçlı olarak kullanıldıklarında beklenen yararı sağlamazlar. Bu yüzden de klasik olarak ve yaygınca kullanılan alkali-silika vb. diyagramların kullanılmasına itibar edilmemiştir. Bunun yerine nispeten daha hareketsiz olan $\mathrm{Fe}$, Ti, Ni, Cr, V, Zr, Nb, Ta ve Hf gibi hareketsiz elementler tercih edilmiştir. Dalmabatma ile ilişkili bazaltlar için iz elementlerin iki değişkenli diyagramlarda kıyaslanması; magma petrojenezinde manto bileşenlerinin dalma ile ilişkili bileşenlerden ayrılmasında oldukça yararlı olarak kullanılmaktadır (Pearce, 1982). Şekil 8E'de Sazak Formasyonu'nun metavolkanik kayaları Th/Yb'a karşı Ta/Yb ikili diyagramında (Pearce, 1983) değerlendirilmişlerdir. 


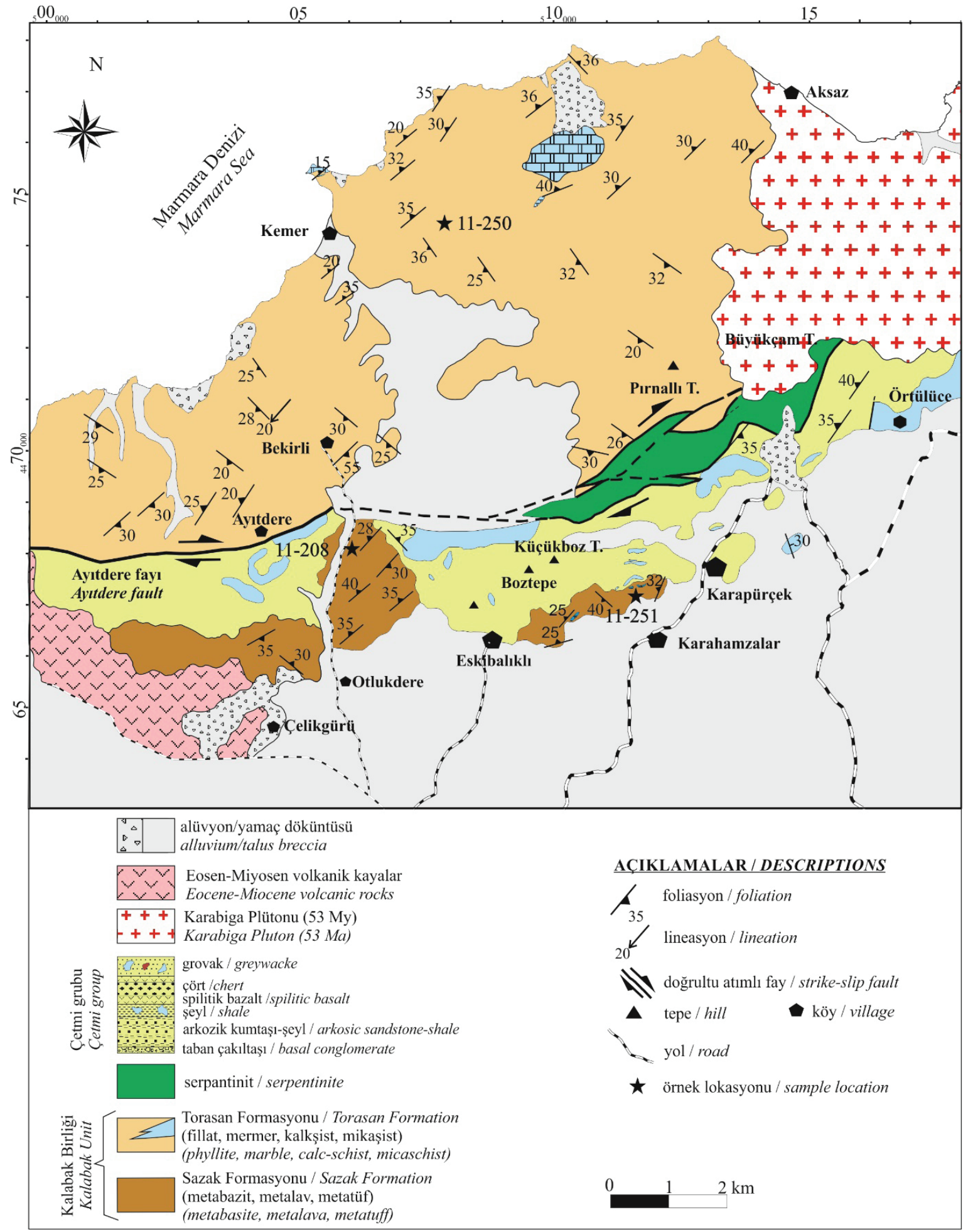

Şekil 7. Karabiga masifinde Kalabak Birliği’ne ait birimlerin dağılımını ve ilişkilerini gösterir jeoloji haritası.

Figure 7. Geological map of Kalabak Unit rocks in the Karabiga massif, showing the distributions and the relationships. 
$\mathrm{Bu}$ diyagramın her iki ekseninde de Yb paydada yer almaktadır. Bu durum; kısmi ergime ve kristal ayrımlaşması işlemlerine bağlı olarak meydana gelen değişimleri büyük oranda ortadan kaldırma yönünde etki yapar. Böylece kaynak bileşimine odaklanma imkanı sağlar (Pearce 1982; 1983). Manto zenginleşmeleri Ta ve Th üzerine eşit olarak etki yaptıklarından; bu diyagramda; okyanus ortası sirt bazaltları ve kirlenmeye uğramamış levha içi bazaltlar iyi belirlenmiş sabit eğimli bir bant içine düşer. Buna karşılık ada yayı ve aktif kıta kenarı bazaltları yüksek $\mathrm{Th} / \mathrm{Yb}$ oranlarına bağlı olarak farklı bir dağılım sunar. Çünkü dalma-batma zonu akışkanları Th'da önemli bir zenginleşme yaratır (Pearce 1982; 1983; Wilson, 1989 ve oradaki referanslar). Bu durum ikili değişken diyagramında dalma-batma ilişkili kayaların dağılım alanında toleyitik, kalkalkalen ve şoşonitik ayırımına da izin vermektedir. Sazak Formasyonu metavolkaniklerinden alınan tüm örnekler bu diyagramda değerlendirildiğinde bunlardan Çamlıca masifindekiler önemli oranda kalkalkalen nitelikli aktif kita kenarı alanına, Karabiga masifinden alınan iki örnek ise zenginleşmiş manto kaynağı ile aktif kıta kenarı alanının sınırına düşmektedir. Bu durum çoklu element (Şekil 8A ve B) ve jeokimyasal adlama diyagramlarında (Şekil $8 \mathrm{C}$ ve D) belirlediğimiz iki grupta volkanizma gelişimi tespitini desteklemektedir.

Öte yandan bu kayalar Hf/3-Th-Ta üçlü tektonik ayrım diyagramında (Şekil 8F; Wood, 1980) değerlendirildiğinde; Sazak Formasyonu'na ait metavolkanitlerin Çamlıca masifindeki örneklerinin kalk-alkalen bazalt alanına, Karabiga masifindeki örneklerinin ise levha içi bazalt alanına düştükleri ve iki ayrı grup oluşturdukları görülmektedir.

Sazak Formasyonu'nun metavolkanik kayalarından (11-208) ve bunlar arasındaki mikaşistlerden (11-251) birer örnek LA-ICP-MS, $\mathrm{U}-\mathrm{Pb}$ zirkon yöntemiyle tarihlendirilmiştir (Şekil 5C ve 5D; Tunç vd., 2012; Yiğitbaş vd., 2014). Mikaşist örneklerinden elde edilen sonuçlar konkordiya diyagramında üç ana jeolojik olayı işaret etmektedir. Diskordiya çizgisi, konkordiya eğrisini iki noktada kesmektedir. Bunlardan üst kesişim noktası (c. $591 \mathrm{My}$ ) protolitin çökelimi için bir maksimum yaşı işaret etmektedir. Alt kesişim noktası (c. $64 \mathrm{My}$ ) ise Alpin orojenezi ile ilgili en son kurşun kaybını göstermektedir. Bir diğer kurşun kaybı dönemi de yaklaşık $300 \mathrm{My}$ dolayında olmuştur (Şekil 5C). Sazak Formasyonu mikaşistlerinde kurşun kaybından etkilenmemiş en genç zirkon popülasyonu kullanılarak elde edilen protolitin maksimum çökelme yaş ise 582 \pm 30 My’dır (Şekil 5C).

Metavolkanik örnekten elde edilen sonuçlar da mikaşist örneklerinde olduğu gibi üç ana jeolojik olayı işaret etmektedir (Şekil 5D). Bunlardan üst kesişim noktası (c. 572 My) protolitin kristalizasyon yaşını gösterirken, alt kesişim noktası (c. 60 My) ise Alpin orojenezi ile ilgili en son kurşun kaybı olarak değerlendirilmiştir. Üçüncü önemli jeolojik olay ise yaklaşık 340 My dolayındadır. Metavolkanik örnekte kurşun kaybından etkilenmemiş en genç zirkon popülasyonu kullanılarak elde edilen protolitin kristalizasyon yaşı ise $577 \pm 20$ My'dır (Şekil 5D). Bu yaş bir yandan Sazak Formasyonu mikaşistlerine ait protolitin maksimum çökelme yaşı ile ve diğer taraftan Dedetepe Formasyonu'na ait mikaşistlerden ve eklojitlerden alınan yaşlarla uyumludur. Yaklaşık 340 milyon yıla karşılık gelen ve kurşun kayb1 ile kendini gösteren tektonotermal etki hem Sazak Formasyonu'nun mikaşist ve metavolkaniklerinde ve hem de Dedetepe Formasyonu'na ait tüm birimlerde ortak bir özellik olarak görülmektedir.

\section{Torasan Formasyonu}

Torasan Formasyonu adı da tıpk1 Sazak Formasyonu gibi; bu çalışmada kullanıldığı anlam ve konumuna en yakın manada ilk kez Duru vd. (2012) tarafindan kullanılmıştır. Ancak bu birim daha önce Okay vd. (1990) tarafindan çok farklı anlamda; Karakaya kompleksi içindeki bir 
tektonik ünite olarak "Torasan metamorfitleri" ad1 ile tanıtılmıștır. Birimin sadece Havran-Edremit arasındaki yüzeylemeleri ise yine Okay vd. (1990) tarafindan Kalabak Formasyonu adı altında ve "Karakaya öncesi birim” olarak tanımlanmıştır.

Torasan Formasyonu, başlica çoklu deformasyona uğramış, karakteristik gümüşi gri renkli mikaşist, fillat ve kuvars mikaşistlerden oluşur. Birim içerisinde metapelitikmetasedimenter kayalarla yanal ve düşey geçişi izlenebilen, yer yer koyu gri ve yer yer de beyaz renkli, iyi tabakalanmalı mermerler bulunmaktadır. Birimin özellikle Sazak Formasyonu'na yakın alanlardaki yüzleklerindeki fillatlar daha çok kahvemsi sarımsı renklerde olup yine kahvemsi sarı renkli metabazit ve metatüf aradüzeyleri ve mercekleri içermektedir.

Birimin en ilginç özelliklerinden biri de içerisinde metre mertebesinden haritalanabilir büyüklüklere kadar değişen boyut ve kalınlıklarda metaofiyolit dilimleri içermesidir. Bunlargenellikle serpantinitlerle temsil edilmekte, yanı sira metagabro-amfibolit mercekleri de görülmektedir. $\mathrm{Bu}$ ofiyolitik kayaların haritalanabilir boyutta olan yüzlekleri önceki çalışmalarda Denizgören (meta) ofiyoliti adı altında tanıtılmıştır (Okay vd., 1990; 1991; Beccaletto, 2004; Duru vd., 2012).

Çamlıca masifinde Torasan Formasyonu fillat, mermer ve kalkşist ardalanmasından oluşmaktadır. Arazide uzaktan yeşil, gri, kirli sarı renklerde görünümü olan bu formasyon ince taneli ve belirgin foliasyona sahiptir. Foliasyon düzlemleri genellikle KD-GB doğrultulu olup $25-30^{\circ}$ ile $\mathrm{KB}^{\prime}$ ya eğimlidir. Klorit fillat ve mikaşistlerle birlikte bulunan mermerler değişik kalınlıklarda mercekler şeklindedir.

Çamlıca masifinde Torasan Formasyonu'na ait birimlerde kuvars + muskovit + klorit + epidot + kalsitten oluşan bir mineral parajenezi tespit edilmiştir. Buna göre bu alanda birimin metamorfizması yeşil-şist fasiyesi klorit zonuyla başlamakta ve epidotun ortaya çıkmasıyla da biyotit zonu koşullarına geçmektedir.

Torasan Formasyonu, Çamlica masifinin kuzey ve kuzeybatısında metaofiyolitik kayalarla yaygınca dilimlenmiştir (Şekil 3 ve 4). Ayrıca daha kuzeybatıda Nusretiye (UTM 35S 0494500 E-4361400 N) ve Dumanlı (UTM 35S 0491100 E-4357050 N) köyleri arasındaki alanda şistlerin içerisinde KB-GD uzanımlı serpantinit dilimleri bulunmaktadır. Bunların boyutları yer yer 500 metre genişlik ve $2 \mathrm{~km}$ uzunluğa kadar erişebilmektedir (Şekil 9).

Biga Yarımadası'nın en batı kesimlerinde; Geyikli-Behramkale arasındaki alanda da Torasan Formasyonu karakteristik gümüşi renkli metapelitik şist ve mermerlerden oluşur (Şekil 1). Yer yer serpantinit ve metagabro-amfibolitlerle değişik boyutlarda dilimlenmiştir. Birim çoklu deformasyona ve yeşil-şist fasiyesi koşullarında metamorfizmaya uğramıştır.

Bazı çalışmalarda (örn. Okay vd. 1990; b; Beccaletto ve Jenny, 2004) bu birim; Permiyen yaşl1 karbonatların altında yer alan ve bu karbonatlarla dereceli geçişli olan düşük dereceli metamorfik fillat ve mikaşistlerle birlikte değerlendirilmiş ve haritalanmıştır. Böylece; bir açısal uyumsuzluğun iki tarafindaki benzer nitelikli metapelitik kayalar yanlışlıkla aynı formasyon içinde haritalanmış ve değerlendirilmiştir.

Birime ait litolojiler Geyikli beldesi ve çevresinde Kestanbol granitoyidinin batısında Akçakeçili ve Tavaklı köyleri arasında ve güneyde Kulfa köyü civarında Tersiyer birimlerinin altından ayrı ayrı küçük yüzleklerde görülürler ve böylece birim yarımadanın en güneybatı kesimlerine, Ayvacık dolaylarına kadar izlenebilir (Şekil 1). 

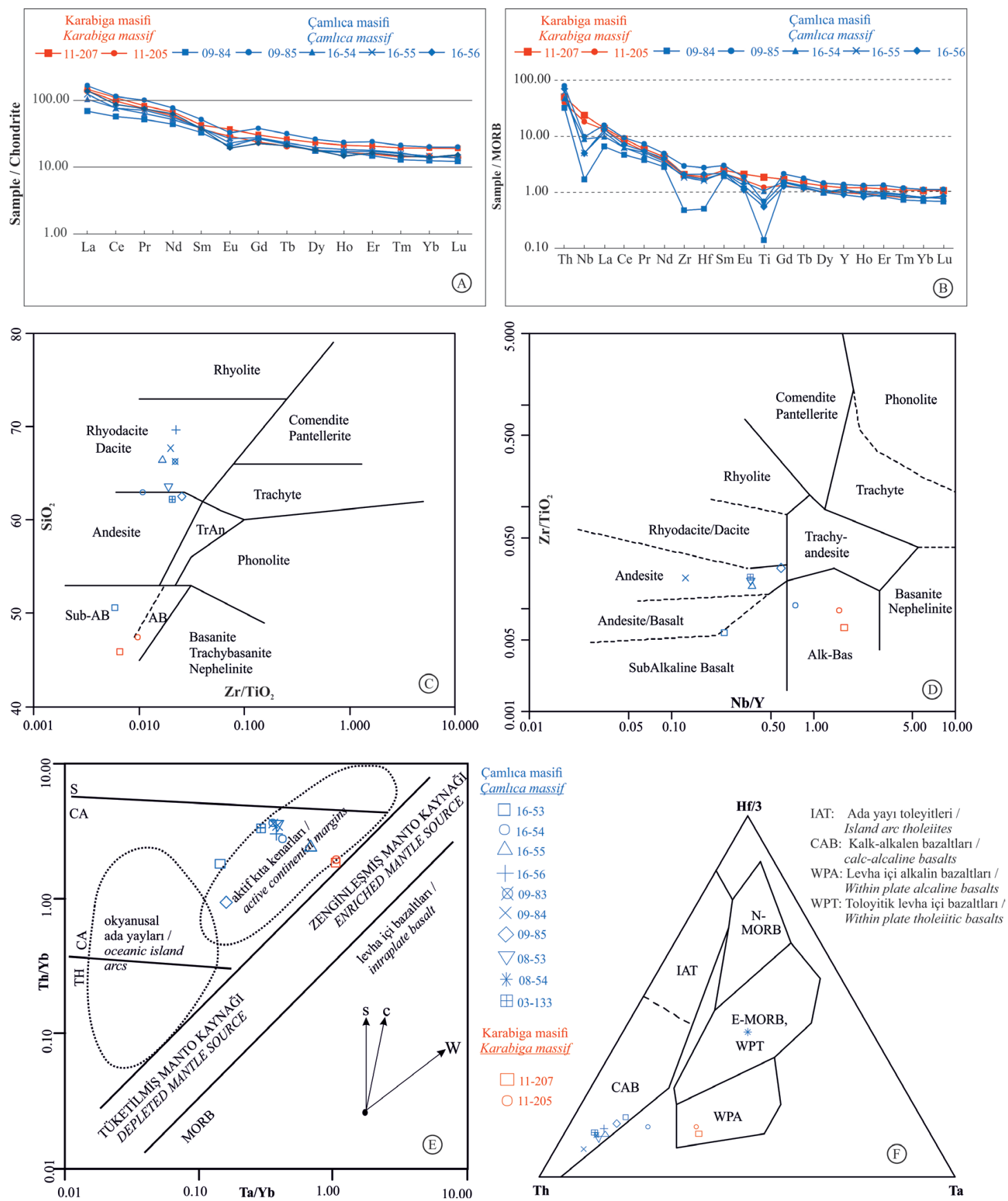

Şekil 8. Sazak Formasyonu metavolkanik kayalarının jeokimyasal karakterini gösterir A) Kondrite göre normalize edilmiş REE ve B) MORB'a göre normalize edilmiş çoklu element diyagramları, $\mathbf{C}$ ) $\mathrm{Zr} / \mathrm{TiO}_{2}$ ye karşı $\mathrm{SiO}_{2}$ (Winchester ve Floyd, 1977) ve D) $\mathrm{Nb} / \mathrm{Y}$ ye karşı $\mathrm{Zr} / \mathrm{TiO}_{2}$ (Winchester ve Floyd, 1977) sınıflandırma diyagramları, E) $\mathrm{Ta} / \mathrm{Yb}$ ye karşı Th/Yb (Pearce, 1983) ve F) Th-Hf/3-Ta (Wood, 1980) tektonik ayrım diyagramları.

Figure 8. Diagrams, showing the geochemical character of metavolcanic rocks from the Sazak Formation, A) Chondrite normalized REE and B) MORB normalized multi-element diagrams, $\mathrm{C}$ ) $\mathrm{Zr} / \mathrm{TiO}_{2}$ vs. SiO (Winchester and Floyd, 1977) and D) $\mathrm{Nb} / \mathrm{Y}$ vs. $\mathrm{Zr} / \mathrm{TiO} \mathrm{O}_{2}$ (Winchester and Floyd, 1977) classification diagrams, E) $\mathrm{Ta} / \mathrm{Yb}$ vs. Th/Yb (Pearce, 1983) and $\boldsymbol{F})$ Th-Hf/3-Ta (Wood, 1980) tectonic discrimination diagrams. 


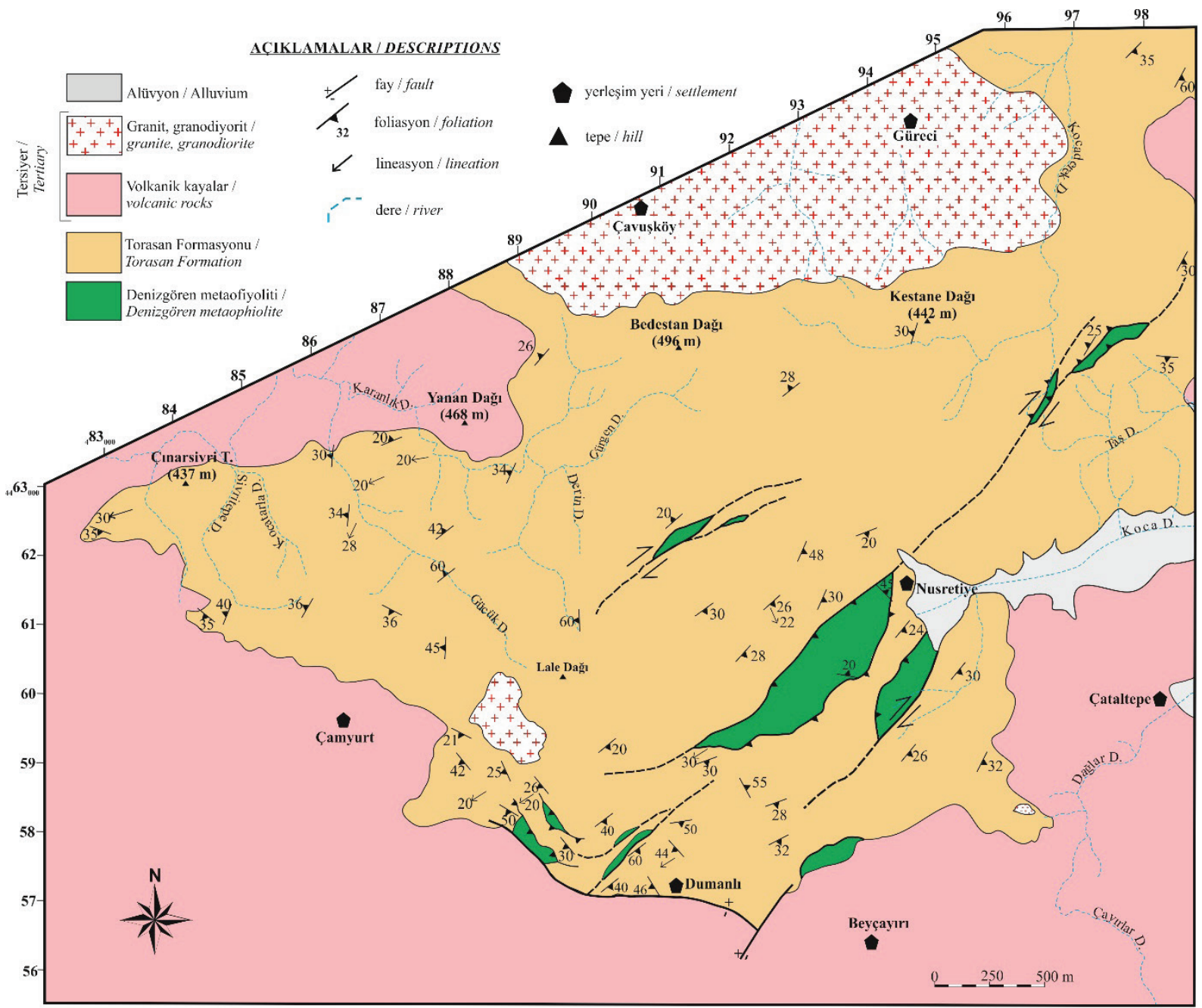

Şekil 9. Karabiga masifinin güneybatı ucunda Nusretiye-Dumanlı arasındaki alanın jeoloji haritası

Figure 9. Geological map of the southwest end of the Karabiga massif between Nusretiye and Dumanl villages.

Tavaklı doğusundaki Kayhan Mahallesi (Şekil 1) ve dolayında Torasan Formasyonu'nun Permiyen karbonat istifi tarafindan açısal uyumsuzlukla örtüldüğü görülür (Şekil 10). Kayhan Mahallesi; gümüşi, parlak gri renkli çok iyi yapraklanmalı, sık ve aşırı kıvrımlı fillatşistler üzerinde yer alır (Şekil 10C). Mahallenin terkedilmiş evlerinden sonra kuzeydoğuya doğru orta ince tabakalı, çok düşük dereceli metamorfik, gri-pembemsi kırmızımsı gri renkli, sedimenter kökeni tanınabilen, tabakalanması ve taneleri belirgin bir metakumtaşı yüzeyler (Şekil 10A). Bu kumtaşları üste doğru tane boyu incelip silttaş1 ve şeyle geçerek ve karbonat oranı artarak önce rekristalize killi kireçtaş1-kireçtaş1 merceklerine ve daha sonra da Permiyen'in fosilli kireçtaşlarına geçer (Şekil 10C). Üstteki bu yalın yapıl1, iyi tabakalı, kırıntılı kayalar Permiyen istifinin tabanını oluşturur ve altındaki çoklu deformasyonlu, nispeten çok daha ileri derecede metamorfik gümüşi renkli mikaşistler (Şekil 10D) üzerinde açısal uyumsuzlukla oturur.

Biga Yarımadası batısındaki Bozcaada'nın doğu kıyılarında da benzeri bir mermer-mikaşistfillat istifi yüzeylemektedir. Bu alanda mermerler 
beyaz renkli, kalın katmanlı; şist ve fillatlar ise karakteristik gümüş grisi renkli ve çok iyi yapraklıdır. Şist ve fillatlar çoklu deformasyona maruz kalmış olup serpantinitlerle metre mertebesinden birkaç on metre mertebesine kadar dilimlenmişlerdir. Bu yüzlekler, ofiyolitik kayalar içermesi nedeniyle önceki çalışmalarda (Temel ve Çiftçi 2002; Kesgin ve Varol, 2003; Dönmez vd., 2008; Akçay vd., 2008) ve 1/500.000 ve 1/100.000 ölçekli Türkiye Jeoloji Haritası paftalarında "Denizgören ofiyoliti”, “Çetmi melanjı" vb. birimler olarak gösterilmiştir. Oysa bu alanlardaki birimleri oluşturan litolojiler Çamlıca masifindeki ve Geyikli dolaylarındaki Torasan Formasyonu'na çok benzer niteliklere sahiptir. Bu nedenle Bozcaada'daki bu yüzlekler de Torasan Formasyonu'nun batı devamı olarak değerlendirilmelidirler.

Ayrı ayrı yüzleklerde yapılan gözlemler sonucunda Torasan Formasyonu'nun genel nitelikleri şöyle özetlenebilir: Grimsi-mor, gümüşi renkli metakumtaşı, metakonglomera, fillat, kuvars-mikaşist, açık yeşil kalkşist, beyaz mermer ve kuvarsitler birimin tipik litolojileridir. $\mathrm{Bu}$ birimlerin geçirdikleri metamorfizmaya rağmen yer yer ilksel sedimanter özellikleri korunabilmiştir. Birim içerisinde özellikle karbonat ara düzeylerinin bulunduğu kesimlerde tabakalanma farkedilebilmektedir. Birim başlıca kalsit-kuvars-muskovit şist, kuvars-muskovit şist, kuvars-mika şist, kalkşist, kuvars-muskovit mermer bileşenlerinden oluşmaktadır. Birim içerisinde çoklu deformasyona bağlı sık ve çeşitli yönde ve türde kıvrımlanma gelişmiş olup doğal olarak foliasyon konumlarında sik değişimler görülmektedir. Tıpk1 Çamlıca ve Karabiga masiflerinde olduğu gibi yarımadanın pek çok yerindeki ve Bozcaada' daki yüzleklerinde birimin serpantinitlerle dilimlendiği yerler (Çamdere ve Bozcaada gibi) vardır. Birim Kayhan mahallesi çevresinde açıkça görüldüğü gibi Permiyen kireçtaşlarının tabanındaki kırıntılı seviye tarafından açısal uyumsuzlukla örtülmektedir (Şekil 1 ve 10).

Bazı çalışmalarda; üzerindeki Permiyen yaşlı karbonatlarla uyumlu görüldüğünden birime Permiyen yaşlar uygulanmıştır (Okay vd. 1990; Beccaletto, 2004; Beccaletto ve Jenny 2004). Öte yandan Duru vd. (2012) ise Geyikli Formasyonu ile üzerindeki karbonat istifini birbirinden ayırarak araya uyumsuz dokanak koymuşlardır. Duru vd (2012), mikaşist düzeylerindeki muskovitlerden $531 \pm 86 \mathrm{My} \mathrm{Rb} / \mathrm{Sr}$ radyometrik yaşı elde ederek birimin erken Kambriyen'de metamorfizma geçirdiğini ve yaşının ise erken Kambriyen veya Prekambriyen olması gerektiğini ileri sürmüşler, ancak tek bir örnekten elde edilen bu yaşın başka örneklerde de teyid edilmesi gerektiğini ifade etmişlerdir. $\mathrm{Bu}$ çalışmada da bu düzeylerden benzer yaşlar elde edilmiştir (Şekil 5E).

Torasan Formasyonu, Edremit ile Bandirma arasındaki alanda Çamlık metagranodiyoritleri tarafindan kesilmektedir. Her ne kadar Kalabak ve Fazlıca köyleri arasındaki alanda bu iki birimin birincil dokanağı tektonik olarak bozulmuş olsa da Çamlık metagranodiyoritinin yüzeylediği Fazlıca, Tarlabaşı, Kocaseyit köyleri ve dolaylarında metagranodiyoritler içinde Torasan Formasyonu'na ait anklavlar bulunmaktadır. Ayrica bu alandan daha kuzeyde Kircaoba köyüne kadarki yaklaşı $15 \mathrm{~km}$ boyunca bu iki birim arasındaki sınır oldukça düzensiz, girintili çıkıntılı ve birbirleriyle girifttir ve dokanakta kontak metamorfizma zonu gelişmiştir. Kontak metamorfizmaya rağmen; her iki birimde gelişmiş olan metamorfik foliasyonun bu dokanak boyunca birinden diğerine kesiksiz devam ettiği, birbirinin devamı olduğu görülebilmektedir. $\mathrm{Bu}$ nedenle Torasan Formasyonu ve Çamlık metagranodiyoritinin intrüzif dokanakla bir araya gelmelerinden sonra birlikte metamorfizmaya uğradıkları anlaşılmaktadır. Bu ilişki çok daha kuzey-kuzeydoğuda Bandırma dolaylarına kadar saha gözlemlerimizle takip edilmiştir (Yiğitbaş vd., 2018a; Aysal vd., 2012a ve b). 


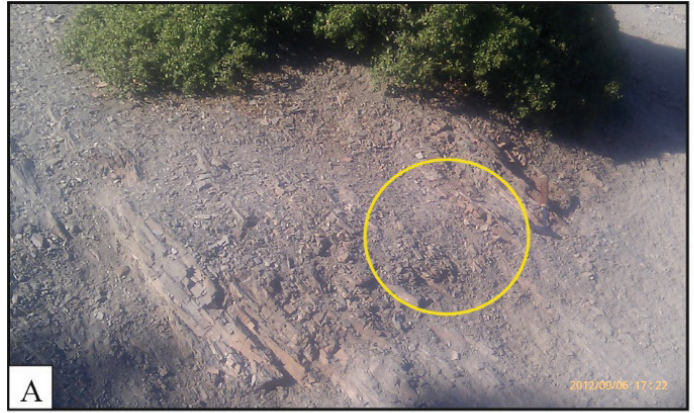

Geyikli Formasyonu / Geyikli Formation mikaşist, fillat, mermer / micaschist, phyllite, marble
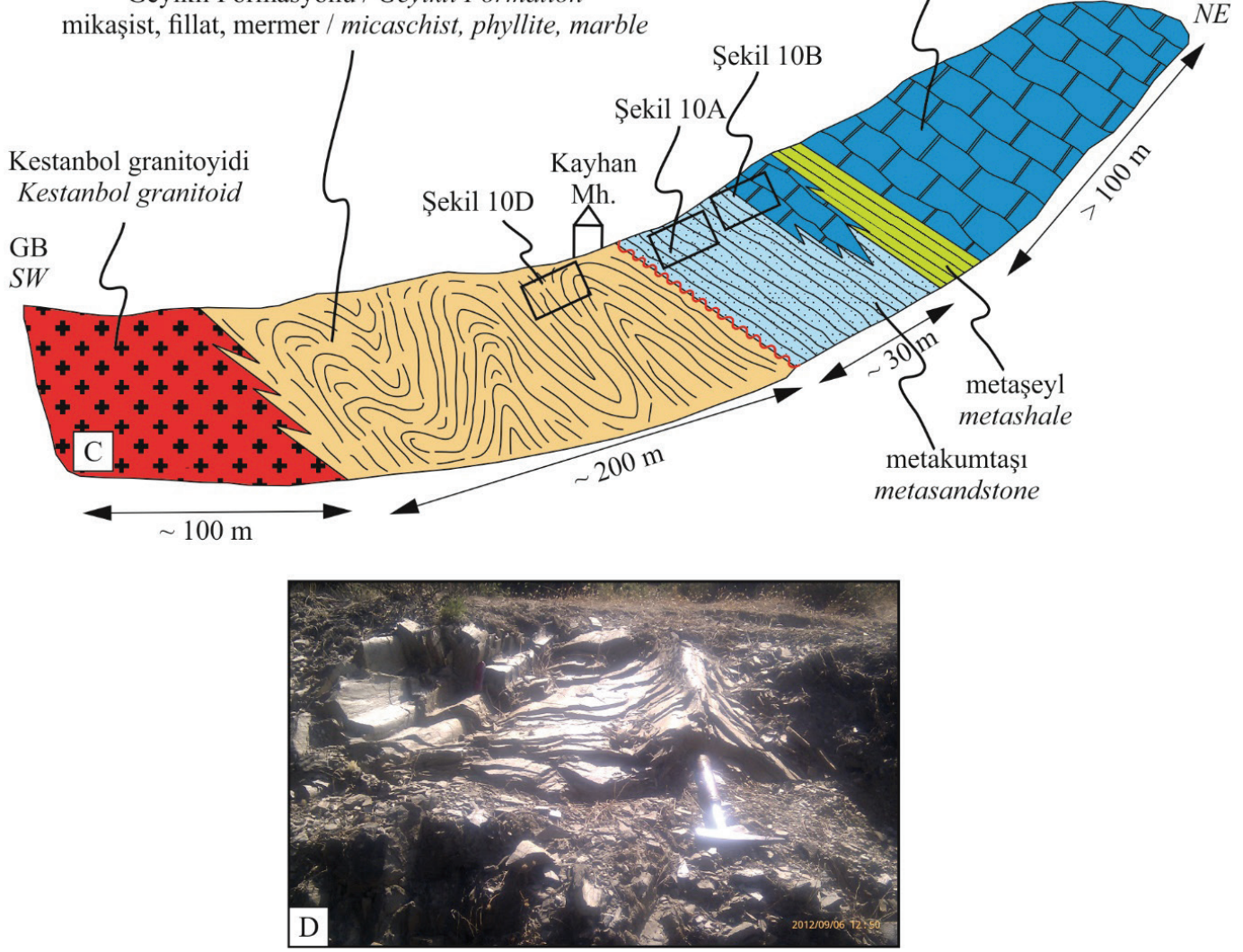

Şekil 10. A) Kayhan mahallesi dolayında temel metamorfik kayalar üzerine açısal uyumsuzlukla gelen zayıf metamorfik metakumtaşı düzeyinin yakından görünüşü, B) Bu metakumtaşlarının üste doğru Permiyen yaşlı fosilli rekristalize kireçtaşlarına geçtiği lokasyona bakış, C) Kayhan mahallesi civarında temel kayaları ile bunlar üzerine gelen düşük dereceli metamorfik kırıntılı kayaların ilişsisini gösterir skeç kesit, D) Kayhan mahallesi dolayında iyi foliasyonlu, polifaz deformasyona maruz kalmış şist ve fillatların mostra görünümü.

Figure 10. A) A close-up view of the low-grade metamorphic metasandstone level, overlying the basement metamorphic rocks with an angular unconformity around the Kayhan neighborhood, B) Overview of the location where these metasandstones pass upwards into Permian fossilized recrystallized limestones, $\boldsymbol{C})$ Sketch cross-section showing the relationship between the basement rocks and the overlying low-grade metamorphic clastic rocks around the Kayhan neighborhood, D) Outcrop view of well-foliated and polyphase deformed schist and phyllites around the Kayhan neighborhood. 
Torasan Formasyonu'nun Karadağ, Çamlıca ve Karabiga masiflerindeki yüzleklerinden alınan mikaşist örneklerinden LA-ICP-MS, U-Pb zirkon yaş tayini yapılmıştır. Mikaşist örneklerinden elde edilen sonuçlar üç ana jeolojik olayı işaret etmektedir (Şekil 5E). Diskordiya çizgisi, konkordiya eğrisini iki noktada kesmektedir. Bunlardan üst kesişim noktası (c. $536 \mathrm{My}$ ) protolitin çökelimi için bir maksimum yaşı işaret etmektedir. Alt kesişim noktası (c. $45 \mathrm{My}$ ) ise geç Alpin orojenezi ile ilgili en son kurşun kaybını göstermektedir. Öte yandan daha önceki bir diğer kurşun kaybı dönemi de yaklaşık 340 My dolayında olmuştur. Torasan Formasyonu mikaşistlerinde kurşun kaybından etkilenmemiş en genç zirkon popülasyonu kullanılarak elde edilen protolitin maksimum çökelme yaşı ise

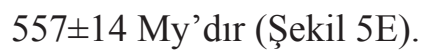

\section{Çamlık metagranodiyoriti}

Birim başlica yeşil-şist fasiyesinde metamorfizmaya uğramış bir granit, granodiyorit topluluğundan oluşur. Daha önceleri Bingöl vd. (1975), Krushensky vd. (1980), Gümüş (1964), Aslaner (1965) tarafından da çeşitli biçimlerde tanımlanmış olmakla birlikte ilk kez Havran kuzeyindeki yüzleklerden Çamlık metagranodiyoritleri olarak Okay vd. (1990) tarafından adlanmıştır.

Birimin en geniş yüzeylemesi Havran kuzeyindeki Fazlıca-Kocaseyit köyleri dolayından daha kuzeybatıdaki Kırıklar köyüne kadarki yaklaşık $25 \mathrm{~km}$ boyunca görülür. Bir diğer yüzeyleme ise Eybek dağ 1 kuzey eteklerinde $4 \times 5$ $\mathrm{km}$ boyutlarındadır. Gerek litolojik nitelikleri ve gerekse sokulum ilişkisi içinde olduğu metamorfik Torasan Formasyonu ile mekansal birlikteliği bakımından Çamlık metagranodiyoritinin eşdeğeri yüzlekler daha kuzeydoğuda Torasan köyü kuzeyinde, Camialan köyü dolaylarında ve Karacabey kuzeyinde de bulunmaktadır. Nitekim

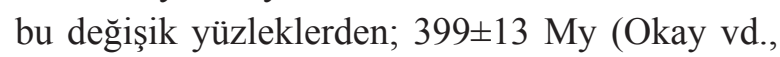

1996), 389 \pm 2 My ve $401 \pm 4.8$ My (Aysal vd., 2012a), 393.8 \pm 2.7 My-395.9 \pm 4.09 My (Sunal, 2012) ve $400.3 \pm 1.4$ My (Aysal vd., 2012b) gibi birbiriyle uyumlu yaşlar elde edilmiştir. Dolayısıyla literatürde Çamlık metagranodiyoriti, Yolindi metagranodiyoriti, Karacabey metagraniti, vb. adlarla anılan ve Kalabak Birliği kayalarıyla mekansal ilişkili metamorfik granitik kayalar benzer yaş ve tektonik anlama sahiptirler. Birim Kocaseyit (Çamlık) köyü güneyinde (UTM 35S 0515864 E-4384330 N) Triyas yaşlı taban çakıltaşları tarafından uyumsuzlukla örtülmektedir.

Çamlık metagranodiyoriti bölgesel jeolojinin anlaşılması bakımından kritik öneme sahip bir birimdir. Çünkü; 1) yaşı Triyas ya da geç Paleozoyik olarak kabul edilen (Okay vd., 1990; Duru vd., 2012) birimleri kestiğinden bu birimlerin üst yaşının erken Devoniyen ile sınırlanmasını sağlamıştır. 2) Biga Yarımadası'nda metamorfik tektonostratigrafinin Kazdağ Birliği'ne nazaran daha üst birimi olan Kalabak Birliği'ni kesmesine rağmen bunun altında tektonik dokanakla yer alan ileri derecede metamorfik çekirdek kayalarını (Kazdağ Birliği) kesmemektedir. Bu da; Kazdağ Birliği kayalarının bölgeye yerleşmesinin ve hatta protolit yaşının daha genç olmasını gerektirmektedir (Yiğitbaş vd., 2018a; Yiğitbaş vd, hazırlanmakta).

\section{TARTIŞMA}

$\mathrm{Bu}$ makalede tanıtıldığı biçimiyle Kalabak Birliği; 1) Dedetepe Formasyonu, 2) Sazak Formasyonu, 3) Torasan Formasyonu ve 4) Çamlık metagranodiyoriti birimlerinden oluşmaktadır. $\mathrm{Bu}$ birimlerden Sazak ve Torasan formasyonları ile Çamlık metagranodiyoriti Kazdağ antiformunun güneydoğu ve doğu kesimlerinde haritalanmış birimlerdir (Duru vd., 2012; Aysal vd., 2012a ve b). Çamlıca ve Karabiga masifleri ile Kazdağ yükseliminin kuzey kesimlerinde de bu birimlerin benzerlerinin bulunduğu ve yaşlarının daha önce 
ifade edilenlere nazaran çok daha eski olduğu (geç Prekambriyen-erken Paleozoyik) ilk kez Tunç vd. (2012) ve Yiğitbaş vd. (2014) tarafından analitik ve stratigrafik verilerle ortaya konulmuştur.

$\mathrm{Bu}$ makalede Duru vd. (2012) tarafindan kullanılan stratigrafik adlamalara mümkün mertebe uymaya çalışılarak Kalabak Birliği birimlerine Dedetepe Formasyonu da dahil edilmiştir. Dedetepe Formasyonu, içerisinde eklojit ve mavi şist blok ve tektonik merceklerinin de yer aldı $\breve{g}_{1}$ bir metamorfik dalma-batma mélanjıdır. Gerek içerisindeki eklojitik kayalardan ve gerekse bunların etrafinı saran mikaşistlerden alınan $\mathrm{U}-\mathrm{Pb}$ zirkon yaşları bu mélanjın geç Ediyakaran döneminde (565 \pm 9 My) geliştiğini göstermektedir. Birim, Biga Yarımadası'nın kuzeyindeki Çamlıca masifinin görülür temel birimini oluşturmaktadır. Sazak ve Torasan formasyonları Dedetepe Formasyonu'nun üzerine tektonik dokanakla gelmektedir. Andezitik ve bazaltik volkanik topluluklarla temsil edilen Sazak Formasyonu'nun petrografik ve jeokimyasal karakteri iki ayrı tektonik ortama işaret etmektedir. Sazak Formasyonu Çamlıca masifinde başlıca subalkalen bazalt-andezit-dasit-riyolit dizisi ile temsil edilen bir aktif kıta kenarı volkanizmasını yansıtırken, Sazak Formasyonu'nun Karabiga masifindeki mostraları ise alkali bazalt karakterinde olup levha içi okyanusal ada bazaltlarını temsil etmektedir. $\mathrm{Bu}$ durum Çamlica ve Karabiga masiflerinde birbirinden ayrı alanlarda yüzeyleyen fakat benzer yaşlı volkanik kayaların daha sonraki çalışmalarda iki ayrı formasyon olarak adlanmalarını gerektirebilecektir.

Çamlıca masifindeki Sazak Formasyonu yüzeylemeleri düşey ve yanal yönde Torasan Formasyonu'nun mikaşist ve fillatlarıyla dereceli geçişlidir. Bu mikaşistlerden de geç Ediyakaran

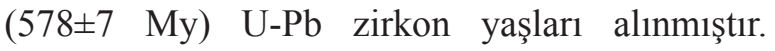
Karabiga masifinde ise bizzat metavolkanik kayalardan $577 \pm 20 \mathrm{My} \mathrm{U}-\mathrm{Pb}$ zirkon yaşı elde edilmiştir (Tunç vd., 2012; Yiğitbaş vd., 2014).
Tüm mikaşist örneklerindekiNeoproterozoyik (11-181 ile 11-184 numaralı örnekler için 816580 My ve 11-168, 11-250 ile 11-253 numaral1 örnekler için 998-580 My) yaşlı zirkon tanelerinin Proto-Tetis okyanusu tabanındaki litosferik levhanın güneye dalması ve Doğu Afrika (PanAfrikan) orojenezi (Şekil 11A; Kröner, 1984; Stern, 1994; Kröner ve Stern, 2005; Kusky, vd., 2003; Murphy vd., 2004a; Nance vd., 2008) ile ilişkili Arap-Nubiyan Kalkanı'ndan sağlanmış olması muhtemeldir.

Birbiriyle uyumlu bu geç Ediyakaran yaş verisi; bir dalma-batma mélanj1, bir aktif kıta kenarı volkanizması ve bir levha içi okyanusal ada alkali bazalt volkanizması gibi farklı tektonik ortamları temsil eden bu birimlerin aynı zaman aralığında gelişmiş olduklarını göstermektedir (Şekil 11B). Mikaşistlerdeki zirkon kaynağının Doğu Afrika-Gondwanaland olduğu düşünülürse geç Ediyakaran döneminde Gondwanaland kuzeyindeki bir okyanusal kabuk ve bu kabuğun güneye dalarak yitimi esnasında gelişmiş olan bir mélanj ve onun da güneyindeki bir Şili tipi yay volkanizması mevcut olmalıdır. Bütün bu ortamların okyanusun kapanmas sürecinde tektonikle bir araya gelmeleri erken Devoniyen öncesidir (Şekil 11B). Çünkü Çamlık granodiyoritleri Biga Yarımadası'nın çeşitli kesimlerinde bu farklı birimleri kesmektedir (Duru vd., 2012; Aysal vd., 2012a ve b; Yiğitbaş vd., 2018a). Kalabak Birliği'ni oluşturan birimlerdeki $\mathrm{U}-\mathrm{Pb}$ zirkon analiz sonuçları bu birimlerin erken Devoniyen öncesinde bir araya geldikten sonra erken Karbonifer dönemindeki bir tektonotermal olaydan da topluca etkilendiklerini göstermektedir. Bu da, Sakarya zonunda varlığ bilinen Variskan (?) (Okay vd., 1996; 2006; Okay ve Topuz, 2017; Göncüoğlu, 2010) veya PaleoTetis (Şengör vd., 2019) tektonomagmatizmasının Biga Yarımadası'ndaki etkileri olmalıdır.

Türkiye'nin kuzeybatı kesimlerinde geç Prekambriyen yaşlı bir diğer yay volkanizması ve ilişkili ofiyolitik topluluklar Sünnice, Almacık 
ve Armutlu masiflerinden tanıtılmıştır (Yiğitbaş vd., 2004). Bu topluluklar 570-590 My yaşl1 yay tipi granitlerle kesilmektedir (Ustaömer, 1999). Biraz daha genç; 546-534 My arasında yaş vermekle birlikte benzeri yay granitleri Istranca masifinde tanıtılmıştır (Yılmaz Şahin, 2014). Güneybat1 Bulgaristan'da Rodop Masifinin kuzeyindeki Kraishte Zonu bir Kadomiyen yay magmatizmasının unsurlarını içermektedir (Kounov vd., 2012). Kraiste Zonu başlıca Morava Nap1, Struma Birimi ve Osogava-Lisets Kompleksi birimlerinden oluşmaktadır. Morava Napı yeşilşist fasiyesinde metamorfik metapelitik kayalarla temsil edilir ve granitle kesilmiştir. Struma Birimi; birbirleriyle dilimlenmiş ofiyolitik ve volkanik kayalarla temsil edilmekte olup ofiyolitik kayalar MORB karakterinde (Haydoutov ve Pin, 1993) ve 620-530 My yaşında (Lilov, 1981), volkanikler ise kalkalkalen nitelikli, bazikten asidiğe değişen volkanik kayalardan oluşmaktadır (Kounov vd., 2012). Kraishte Zonunun bir diğer birimi olan Osogova-Lisets Kompleksi amfibolit, mikaşist, muskovit-biyotit ve amfibol-biyotit gnayslarla temsil edilir. Morava Nap1, Struma Birimi ve Osogova-Lisets Kompleksine ait magmatik kayaların kristalizasyon yaşları 580-540 My aralığındadır (Kounov vd., 2012). Morava Nap1 birimlerini kesen granitik kayalardan alınan yaşlar 577-551 My'dır. Struma Birimi ve Osogava-Lisets Kompleksine ait magmatik kayaların aynı bir kalk-alkalen magma kaynağından türemiş olduğu ve Gondwanaland kıta kenarı boyunca gelişmiş bir magmatik yayı temsil ettiği ortaya konulmuştur (Kounov vd., 2012). Güneybatı Bulgaristan'da tanıtılan bu birimlerin Biga Yarımadası'nda karşılıkları bulunmakta olup (Yiğitbaş vd., 2014; 2018a) geç Ediyakaran-erken Kambriyen kıtasal magmatik yay ortamının ise Kalabak Birliği ile doğrudan benzerlikleri olduğu söylenebilir.

Daha güney alanlara bakıldığında Bitlis Masifi'nde bir And-tipi yay magmatizmasını temsil eden 572 My yaşlı granitler tespit edilmiştir (Ustaömer vd., 2009). Öte yandan Güneydoğu
Anadolu'da otokton Arap platform istifinin görülür temelindeki subalkalen Derik volkanitlerinin de Neoproterozoyik yaşlı (559-581 My) And-tipi bir volkanik yayı temsil ettiği gösterilmiştir (Gürsu vd., 2015). Bu kitasal volkanik yay topluluğu ile kıyaslanabilecek birimlerin Torid-Anatolid kuşağ içinde de bulunduğu ifade edilmektedir (Gürsu ve Göncüoğlu, 2006; Gürsu vd., 2015 ve oradaki referanslar). $\mathrm{Bu}$ alanların hemen tamamında bu volkanik yayın Pan-Afrikan/Kadomiyen sistemi içinde geliştiği konusunda fikir birliği vardır. Alpin dönemin sonuna kadar bölgede gelişen tüm deformasyon fazlarından şiddetle etkilenerek bir orojenik mozayik niteliği kazanan Türkiye'de; bu birbirinden kopuk ve uzak alanlarda yüzeyleyen geç Prekambriyen yaşlı And-tipi Pan-Afrikan/ Kadomiyen yay kuşağı doğaldır ki Variskan (?) ve Alpin tektonik mozayiğin oluşum evreleri esnasında parçalanmış ve bugünkü farklı coğrafyalara dağılmıştır.

\section{SONUÇLAR}

Sakarya Zonu'nun batı ucundaki Biga Yarımadası'nın kuzey kesimlerindeki Karadağ, Çamlıca ve Karabiga masiflerinde Permiyen öncesi bir metamorfik temel bulunur. $\mathrm{Bu}$ metamorfik temel; Kalabak Birliği adı altında toplanmış olup 1) Dedetepe Formasyonu, 2) Sazak Formasyonu, 3) Torasan Formasyonu ve 4) Çamlık metagranodiyoriti olmak üzere 4 birimden oluşur. Bunlardan Çamlık metagranodiyoriti erken Devoniyen yaşında diğerleri geç Ediyakaranerken Kambriyen (?) yaşındadır.

Bugünkü konumuyla görülür en altta yer alan Dedetepe Formasyonu bir dalma-batma mélanjını, Sazak Formasyonu bir aktif kıta kenarını ve Torasan Formasyonu ise bunlarla yaşıt bir çökel istifi temsil etmektedir (Şekil 11B).

Sazak Formasyonu; Çamlıca masifinde başlıca bazalt, andezit, riyodasit vb. subalkalen volkanik ve volkaniklastik kayalarla, Karabiga masifinde ise alkali bazaltlarla temsil edilir. 
Subalkalin kayaların jeokimyasal nitelikleri bu kayaların bir aktif kıta kenarında dalma-batma işlevlerinden etkilenmiş bir volkanik yay ortamına ait olduğunu göstermektedir. Alkali bazaltlar ise okyanusal ada karakterinde olup muhtemelen Proto-Tetis okyanus tabanındaki gelişiminden sonra aktif kıta kenarına eklenmiştir.

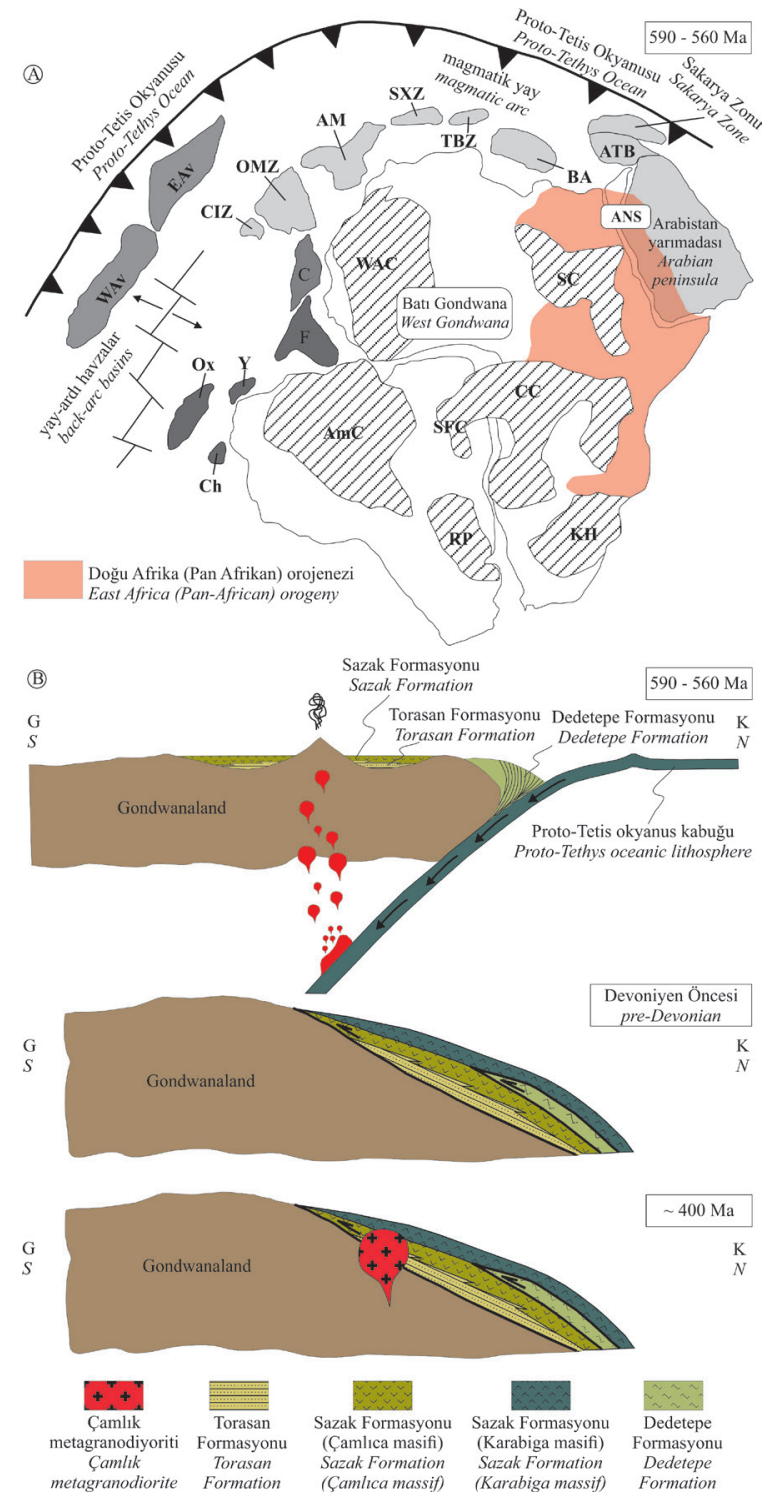

Şekil 11. A) Doğu Afrika (Pan-Afrikan) orojenezi ile ilişkili Gondwana aktif kıta kenarı ve buna bağlı ana peri-Gondwana alanlarının 590-560 My civarındaki palaeocoğrafik rekonstrüksiyonu (Kısaltmalar: ANS: Arap-Nubiyan Kalkanı, AmC: Amazonya Kratonu,
BA: Alplerin temeli, C: Carolina, CC: Kongo Kratonu, KH: Kalahari Kratonu, Ch: Chortis bloğu, CIZ: Merkezi İberya zonu (Iberya), WAv: Batı Avalonya, EAv: Doğu Avalonya, F: Florida, OMZ: Ossa-Morena zonu (Iberya), Ox: Oaxaquia, RP: Ribeira, SC: Sahara Kratonu, SFC: San Fransisco Kratonu, SXZ: SaxoThuringiya Zonu, ATB: Anatolid-Torid Bloğu, TBZ: Tepla-Barrandiya Zonu., WAC: Batı Afrika Kratonu, Y: Yukatan, B) geç Neoproterozoik-erken-orta Paleozoyik döneminde Gondwana kuzey kenarının jeodinamik evrimi

Figure 11 A) Paleogeographic reconstruction of the Gondwana active continental margin and associated main peri-Gondwana areas associated with East African (Pan-African) orogeny around 590-560 Ma (Abbreviations: ANS: Arabian-Nubian Shield, AmC: Amazonia Craton, BA: Basement of the Alps, C: Carolina, CC: Congo Craton, KH: Kalahari Craton, Ch: Chortis Block, CIZ: Central Iberia Zone (Ibreia), WAv: West Avalonia, EAv: East Avalonia, F: Florida, OMZ: Ossa-Morena Zone (Iberia), Ox: Oaxaquia, RP: Ribeira, SC: Sahara Craton, SFC: San Francisco Craton, SXZ: Saxo-Thuringia Zone, ATB: AnatolideTauride Block, TBZ: Tepla-Barrandia Zone, WAC: West African Craton, Y: Yucatan. B) Geodynamic evolution of the northern edge of Gondwanaland during the Late Neoproterozoic - Early-Middle Paleozoic period.

Sonuç olarak Sakarya Zonunun batı ucunda Çamlıca, Karadă ve Karabiga masiflerinde görülür temeli oluşturan metamorfik kayalar ProtoTetis okyanus tabanının güneye, Gondwanaland kıtasının altına dalması esnasında oluşmuş bir mélanj ve aktif kıta kenarı volkanik ada yayı topluluğunu temsil etmektedir (Şekil 11).

\section{KATKI BELİRTME}

$\mathrm{Bu}$ çalışma TÜBİTAK-ÇAYDAG 110Y281 ve 115 Y214 Nolu projeler ile desteklenmiştir. Makalenin editör süreçleri Prof. Dr. Yener Eyüboğlu tarafindan sürdürülmüştür. Prof. Dr. Yener Eyüboğlu'na ve makalenin geliştirilmesine yaptıkları önemli katkılardan dolay1 sayın hakemler Prof. Dr. Ali Polat'a ve Doç. Dr. Fatih Karaoğlan'a teşekkür ederiz. 


\section{EXTENDED SUMMARY}

The Biga Peninsula is one of the areas where composite basement rocks of the Alpine tectonic belt known by names such as the Sakarya continent (Şengör and Yılmaz, 1981; Şengör et al., 2019), Sakarya Zone (Okay et al., 1991), and Sakarya composite belt (Göncüoğlu, 2010) are best observed. The general lines of the geology in the Biga Peninsula are represented by metamorphic basement rocks outcropping in the Kazdağ, Karadăg, Çamlica, and Karabiga massifs and overlying sedimentary and volcanic rocks (Figure 1). Previous studies have named the metamorphic and ophiolitic rocks in the north-northwest section of the peninsula as the 'Ezine Zone', while rocks of the Kazdăg Massif in the south and overlying it were called the 'Sakarya Zone'. The section between these two containing mainly blocky mixed assemblages was named the 'Ayvactk-Karabiga Zone' (Okay et al., 1991; Beccaletto and Jenny, 2004). In this way, this classification, considered to represent different continental basements and the suture (ophiolite/mélange) zone between them, has led to the stratigraphic and structural qualities of each 'zone' being assessed independently of each other.

After all studies to date in the region, remapping and detailed field studies have revealed that the 'zones' mentioned above can be correlated with each other to a significant extent, are not separated by a suture zone and have continuous features with each other in tectonostratigraphic terms.

In terms of tectonostratigraphy, the structurally lowest levels of the sequence in the Biga Peninsula outcrop in the Kazdă Massif (Figures 1 and 2). The Kazdăg Massif extends in northeast direction from the coast of the Gulf of Edremit in the southernmost section of the Biga Peninsula and forms an antiform dipping toward the northeast. The core of this antiform comprises high grade metamorphic basement rocks (Kazdă̆ Unit) with typical gneiss dome appearance. This high grade metamorphic core is tectonically overlain by a weakly metamorphosed Late Precambrian-Early Paleozoic unit (Kalabak Unit) (Tunç et al., 2012; Yiğitbaş et al., 2014). The Kalabak Unit outcrops in all metamorphic massifs in the Biga Peninsula (Karadağ, Çamlica, Karabiga, Kazdăg massifs) and is overlain by Permian and/or Triassic Karakaya Unit with lower metamorphic qualities above an angular unconformity (Figures 1 and 2).

In this article, the focus will be the Kalabak Unit, described as a tectonic unit by us (Yiğitbaş et al., 2018a and b), with the characteristics of rocks forming this unit and their meaning and significance for the geological evolution of the region discussed.

The Kalabak Unit comprises four geological subunits of the 1) Dedetepe Formation, 2) Sazak Formation, 3) Torasan Formation and 4) Çamlık metagranodiorite.

The Dedetepe Formation basically comprises metaophiolite-blueschist-eclogite slices and lenses in a matrix of metapelitic schist, phyllite, gneiss, amphibolite and lower amounts of marble. All these rocks underwent advanced degrees of ductile-semi-brittle shearing and has a complicated sliced appearance. The unit underwent greenschist-amphibolite facies metamorphism. The Dedetepe Formation comprises the lowest tectonostratigraphic unit of the Kalabak Unit (Figures 3 and 4). It underwent more advanced degrees of deformation compared to the overlying Sazak and Torasan Formations and the Dedetepe Formation containing eclogite, blueschist and metagabbro-amphibolite tectonic lenses has the features of heterogeneous-structure metamorphic mélange. Two micaschist samples (11-181 and 11-184) and one eclogite sample (11248) from the Dedetepe Formation were dated with the U-Pb zircon method with Laser Ablation Inductively Coupled Plasma Mass Spectrometry 
(LA-ICP-MS) (Figure 5A and 5B; Tunç et al., 2012; Yiğitbass et al., 2014). Using the youngest zircon population unaffected by lead loss in micaschists, the maximum depositional age for the protolith was $578 \pm 7$ My (Figure 5A). The crystallization age for the protolith obtained using the youngest zircon population unaffected by lead loss in eclogites was 565 18 My (Figure 5B).

The Sazak Formation mainly comprises metatuff and metavolcanic rocks. It contains metavolcanoclastic and marble interlayers. The metamorphic rocks in the Sazak Formation are represented by basalt, dacite and rhyodacite in the Çamlica massif and more often by basalts in the Karabiga massif. The petrographic and geochemical character of the Sazak Formation indicates two separate tectonic environments. The Çamlica massif mainly reflects active continental margin volcanism with subalkaline basaltandesite-dacite-rhyolite series, while outcrops in the Karabiga massif (Figure 7) have alkali basalt character and represent in-plate oceanic island basalts (Figure 8). The metavolcanic rocks and micaschists between them in the Sazak Formation were dated with the LA-ICP-MS U-Pb zircon method (Figure 5C and 5D; Tunç et al., 2012; Yiğitbaş et al., 2014). The maximum depositional age for the protolith obtained from the youngest zircon population not affected by lead loss in micaschist was 582 \pm 30 My (Figure 5C). Using the youngest zircon population unaffected by lead loss in metavolcanics, the crystallization age for the protolith was 577 \pm 20 My (Figure 5D).

\section{The Torasan Formation comprises} characteristic silver-gray color micaschist, phyllite, quartz micaschist and lower amounts of marble which have undergone multiple deformations. Metamorphism is greenschistfacies. One of the most interesting features of the unit is that it contains metaophiolite slices with varying sizes and thicknesses up to mappable dimensions on the scale of meters (Figure 9). These are generally represented by serpentinites in addition to metagabbro-amphibolite lenses. The Torasan Formation is overlain by a Permian carbonate sequence above an angular unconformity (Figure 10). LA-ICP-MS U-Pb zircon age dating was performed on micaschist samples from the Torasan Formation. Accordingly, the maximum deposition age for the protolith obtained using the youngest zircon population unaffected by lead loss in micaschist was 577士14 My (Figure 5E). In fact, the unit is cut by the Çamllk metagranodiorite in the area between Edremit and Bandirma.

Çamlık metagranodiorite mainly comprises a granite and granodiorite assemblage which has undergone mainly greenschist facies metamorphism. Compatible ages of $399 \pm 13 \mathrm{Ma}$

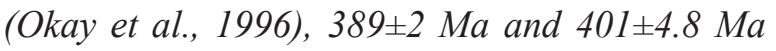

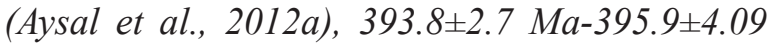
Ma (Sunal, 2012) and 400.3 \pm 1.4 Ma (Aysal et al., $2012 b)$ were obtained for the unit.

In conclusion, detailed investigation of the assemblage forming the Kalabak Unit on the Biga Peninsula show that they represent different tectonic environments like a subduction mélange, active continental margin volcanism and inplate oceanic alkali basalt volcanism and that they developed in these environments in the late Ediacaran period (Figure 11B). If the zircon source in micaschists is considered to be East AfricaGondwanaland, it is understood that a mélange developed during subduction of oceanic crust north of Gondwanaland (Proto-Tethys) toward the south and south of this Chilean-type arc volcanism was present in the late Ediacaran period (Figure 11A). The tectonic assemblage of all these environments occurred with closure of the ocean before the early Devonian (Figure 11B) because the Çamlik granodiorites cut these different units in a variety of sections of the Biga Peninsula (Duru et al., 2012; Aysal et al., $2012 a$ and b; Yiğitbaş et al., 2018a). U-Pb zircon analysis results from units forming the Kalabak Unit (Figure 5) show these units were assembled before the early Devonian and were collectively affected by a tectonothermal 
event in the early Carboniferous period. This may reflect the effects of the Variscan (?) known from the Sakarya Zone (Okay et al., 1996; 2006; Okay and Topuz, 2017; Göncüoğlu, 2010) or PaleoTethys tectonomagmatism (Şengör et al., 2019) in the Biga Peninsula.

\section{ORCID}

Erdinç Yiğitbaş (D) https://orcid.org/0000-0002-0513-9138

Ísmail Onur Tunç (D) https://orcid.org/0000-0002-4273-9175

\section{DEĞİNILEN BELGELER / REFERENCES}

Akçay, A.E., Dönmez, M., Ilgar, A., Duru, M., Pehlivan, Ş., 2008. 1: 100.000 ölçekli Türkiye jeoloji haritaları, Bandırma H 19 paftası No 103, Maden Tetkik ve Arama Genel Müdürlüğü.

Aslaner, M., 1965. Etude Geologique et petrographique de la Region d'Edremit-Havran, MTA Publication No:119.

Aygül, M., Topuz, G., Okay, A.I., Satır, M., Meyer, H.P., 2012. The Kemer Metamorphic Complex (NW Turkey), a subducted continental margin of the Sakarya zone. Turkish Journal of Earth Sciences, 21, 19-35.

Aysal, N., Ustaömer, T., Öngen, S., Keskin, M., Köksal, S., Peytcheva, I., Fanning, M., 2012a. Origin of the Early-Middle Devonian magmatism in the Sakarya Zone, NW Turkey: geochronology, geochemistry and isotope systematics. Journal of Asian Earth Sciences, 45, 201-222.

Aysal, N., Öngen, S., Peytcheva, I., Keskin, M., 2012b. Origin and evolution of the Havran Unit, Western Sakarya basement (NW Turkey): new LA-ICP-MS U-Pb dating of the metasedimentarymetagranitic rocks and possible affiliation to Avalonian microcontinent, Geodinamica Acta, 25 (3-4), 226-247.

Beccaletto, L., 2004. Geology, Correlations and Geodynamic Evolution of the Biga Peninsula, Northwest Turkey. PhD Dissertation, University of Lousanne, $140 \mathrm{~s}$.

Beccaletto, L., Jenny, C., 2004. Geology and Correlation of the Ezine Zone: A Rhodope Fragment in NW Turkey?, Turkish Journal of Earth Sciences, 13, 145-176.
Bingöl, E., Akyürek, B., Kormazer, B., 1975. Geology of the Biga Peninsula and some characteristics of the Karakaya blocky series. In: Congress of Earth Sciences on the occasion of the 50th anniversary of the Turkish Republic, 71-77.

Dönmez, M., Akçay, A.E., Duru, M., Ilgar, A., Pehlivan, Ş., 2008. 1: 100.000 ölçekli Türkiye jeoloji haritaları, Çanakkale H17 Paftası No 101, Maden Tetkik ve Arama Genel Müdürlüğü.

Duru M., Pehlivan Ş., Aral İ. O., Şentürk Y., Yavaş F., Kar H., 2012. Biga Yarımadasının Tersiyer Öncesi Jeolojisi, Maden Tetkik ve Arama Genel Müdürlüğü Yayınları, Özel Yayınlar Serisi, No 28: 7-74.

Gill, R., 2010. Igneous Rocks and Processes: A Practical Guide. Wiley-Blackwell, Chichester, UK, $440 \mathrm{~s}$.

Göncüoğlu, M.C., 2010. Introduction to the Geology of Turkey: Geodynamic Evolution of the Pre-Alpine and Alpine Terranes, Maden Tetkik ve Arama Genel Müdürlüğü Yayınları, 1-69.

Gümüş, A., 1964. Contribution a l'etude geologique de secteur serpentrional de Kalabak Köy-Eymür Köy region D‘Edremit, Turqie, MTA Enstitüsü Yayını, 117, 1-109.

Gürsu, S., Göncüoğlu, C., 2006. Petrogenesis and tectonic setting of Cadomian felsic igneous rocks, Sandiklı area of the Western Taurides, Turkey. International Journal of Earth Sciences, 95, 741757.

Gürsu, S., Möller, A., Göncüoğlu, C., Köksal, S., Demircan, H., Toksoy Köksal, F., Kozlu, H., Sunal, G., 2015. Neoproterozoic continental arc volcanism at the northern edge of the Arabian Plate, SE Turkey. Precambrian Research, 258, 208-233.

Haydoutov, I., Pin, C., 1993. Geochemical and Nd isotope characteristics of pre-Variscan ophiolites and meta-igneous rocks from the Struma Diorite Formation in SW Bulgaria. Geologica Balcanica, $23,51-59$.

Kesgin, Y., Varol, B., 2003. Gökçeada ve Bozcaada'nın Tersiyer Jeolojisi (Çanakkale), Türkiye. Maden Tetkik ve Arama Dergisi, 126, 49-68.

Kounov, A., Graf, J., Quadt, Av., Bernoullia, D., Burg, J.-P., Sewarde, D., Ivanov, Z., Fanning, M., 2012. Evidence for a "Cadomian" ophiolite 
and magmatic-arc complex in SW Bulgaria. Precambrian Research, 212-213, 275-295.

Kröner, A., 1984. Late Precambrian plate tectonics and orogeny: a need to redefine the term Pan-African, (African Geology, Editörler: Klerkx, J., Michot, J.). Tervuren: Musccc. R. I'Afrique Centrale, 2328.

Kröner, A., Stern, R.J., 2004. Pan-African Orogeny, (Encyclopedia of Geology, Editörler: Selley, R.C., Cocks, L.R.M, Plimer, I.R.). Elsevier Academic Press, The Boulevard, Langford Lane, Kidlington, Oxford, OX5 1GB, UK, 1, 1-12.

Krushensky, R., Akçay, Y., Karaege, E., 1980. Geology of the Karalar-Yeşiller area, Northwest Anatolia; U.S. Geological Survey Bulletin, 1461, 72.

Kusky, T.M., Abdelsalam, M., Tucker, R.D., Stern, R.J., 2003. Evolution of the East African and related orogens, and the assembly of Gondwana. Precambrian Research, 123, 81-85.

Lilov, P., 1981. Potassium-argon dating of the Struma Diorite formation north of the town Stanke Dimitrov. Geologica Balcanica, 11, 27-31.

M.T.A., 2012. Biga Yarımadası'nın Genel ve Ekonomik Jeolojisi, (Editörler: Erdoğan Yüzer, Gürkan Tunay). Maden Tetkik ve Arama Genel Müdürlüğü Özel Yayın Serisi, 28, 326 s.

Murphy, J.B., Pisarevsky, S.A., Nance, R.D., Keppie, J.D., 2004a. Neoproterozoic-Early Paleozoic evolution of peri-Gondwanan terranes: implications for Laurentia-Gondwana connections. International Journal of Earth Sciences, 93, 659-682.

Nance, R., Murphy, J., Strachan, R., Keppie, J., GutiérrezAlonso, G., Fernandez-Suarez, J., Quesada, C., Linnemann, U., D’lemos, R., Pisarevsky, S., 2008. Neoproterozoic-early Palaeozoic tectonostratigraphy and palaeogeography of the peri-Gondwanan terranes: Amazonian v. West African connections. Geological Society Special Publication, 297, 345-383.

Okay, A.İ., Siyako, M., Bürkan, K.A., 1990. Biga Yarımadası'nın Jeolojisi ve Tektonik Evrimi. Türkiye Petrol Jeologları Derneği Dergisi, 2 (1), 83-121.

Okay, A.İ., Siyako, M., Bürkan, K.A., 1991, Geology and tectonic evolution of the Biga Peninsula.
Special Issue on Tectonics (ed. J.F. Dewey), Bulletin of the Technical University of Istanbul, 44, 191-255.

Okay, A.İ., Satır, M., Maluski, H., Siyako, M., Monie, P., Metzger, R., Akyüz, S., 1996. Paleoand Neotethyan Events in Northwest Turkey, (Tectonics of Asia, Editörler: Yin, A., Harrison, M.), Cambridge University Press, 420-441.

Okay, A.İ., Satır, M., Siebel, W., 2006. Pre-Alpide and Mesozoic orogenic events in the Eastern Mediterranean region. Memoirs of the Geological Society of London, 32, 389-405.

Okay, A.İ., Topuz, G., 2017, Variscan orogeny in the Black Sea region. International Journal of Earth Sciences, 106, 569-592.

Pearce, J.A., 1982. Trace element characteristics of lavas from destructive plate boundaries. In: Thorpe RS (ed) Andesites. Wiley, New York, 525-548

Pearce, J.A., 1983. Role of sub-continental lithosphere in magma series at active continental margins, (Continental basalts and mantle xenolith, Editörler: Hawkesworth, C.J., Norry, M.J.). Shiva Publications, Cheshire, 230-249

Rollinson, H., 1993. Using geochemical data: evaluation, presentation, interpretation. Longman Geochemistry Series, Harlow, 352 s.

Stern, R.J., 1994. Arc Assembly and Continental Collision in the Neoproterozoic East African Orogen: Implications for the Consolidation of Gondwanaland, Annual Review of Earth and Planetary Sciences, 22, 319-351.

Sunal, G., 2012. Devonian magmatism in the western Sakarya Zone, Karacabey region, NW Turkey, Geodinamica Acta, 25 (3-4), 183-201.

Şengör, A.M.C., Y1lmaz, Y., 1981. Tethyan evolution of Turkey: A plate tectonic approach. Tectonophysics, 75, 181-241.

Şengör, A.M.C., Lom, N., Sunal, G., Zabcı, C., Sancar, T., 2019. The phanerozoic palaeotectonics of Turkey. Part I: an inventory. Mediterranean Geoscience Reviews, 1, 91-161.

Şengün, F., 2005. Salihler, Çamlıca ve Kuşçayırı Çevresinde Yeralan Metamorfik Birimlerin Jeolojisi ve Petrografisi, Çanakkale Onsekiz Mart Üniversitesi, Fen Bilimleri Enstitüsü, Yüksek Lisans Tezi, 115 s., (yayımlanmamış). 
Temel, R.Ö., Çiftçi, N.B., 2002. Stratigraphy and depositional environments of the Tertiary sedimentary units in Gelibolu peninsula and islands of Gökçeada and Bozcaada (Turkey). Turkish Association of Petroleum Geologists Bulletin, 14, 17-40.

Tunç, İ.O., Yiğitbaş, E., Şengün, F., Wazeck, J., Hofmann, M., Linnemann, U., 2012. U-Pb Zircon Geochronology of Northern Metamorphic Massifs in the Biga Peninsula (NW Anatolia-Turkey): New Data and a New Approach to Understand the Tectonostratigraphy of the Region. Geodinamica Acta, 25 (3-4), 202-225.

Ustaömer, P.A., 1999. Pre-Early Ordovician Cadomian arc-type granitoids, the Bolu Massif, West Pontides, northern Turkey: geochemical evidence. International Journal of Earth Sciences, 88 (1), 2-12.

Ustaömer, P.A., Ustaömer, T., Collins, A.S., Robertson, A.H.F., 2009. Cadomian (Ediacaran-Cambrian) arc magmatism in the Bitlis Massif, SE Turkey: magmatismalong the developing northern margin of Gondwana. Tectonophysics, 473, 99-112.

Wilson, M., 1989. Review Of Igneous Petrogenesis: Aglobal Tectonic Approach. Terra Nova, 1 (2), 218-222.

Winchester, J.A., Floyd, P.A., 1977. Geochemical discrimination of different magma series and their differentiation products using immobile elements. Chemical Geology, 20, 325-343.

Wood, D.A., 1980. The application of a Th-HfTa diagram to problems of tectonomagmatic classification and to establishing the natüre of crustal contamination of basaltic lavas of the British Tertiary volcanic province. Earth and Planetary Science Letters, 50 (1), 11-30.

Yaltırak, C., Okay, A. İ., 2004. Edremit Körfezi kuzeyinde Paleotetis birimlerinin jeolojisi. İTÜ Dergisi/d Mühendislik, 3 (1), 67-79.
Yiğitbaş, E., Kerrich, R., Yılmaz, Y., Elmas, A., Qianli, X., 2004. Characteristics and Geochemistry of Precambrian Ophiolites from the Western Pontides, Turkey: Following the Missing Chain of the Precambrian South European Suture Zone to the East. Precambrian Research, 132 (1-2), 179206.

Yiğitbaş, E., Şengün, F., Tunç, İ.O., 2009a. Biga ve Gelibolu Yarımadaları'nda Yüzeyleyen Mesozoyik Yaşlı Kaya Topluluklarının Jeolojisi ve Stratigrafik Özellikleri. TÜBİTAK ÇAYDAG108Y232 Nolu Proje Raporu.

Yiğitbaş E., Tunç, İ.O., Şengün F., 2009b. Biga Yarımadası'nda Bazı Temel Jeolojik Sorunlar. 62. Türkiye Jeoloji Kurultayı (13-17 Nisan 2009), Bildiri Özleri Kitabı, 458-459.

Yiğitbaş, E., Şengün, F., Tunç, İ.O., 2014. Biga Yarımadası'nda (KB Anadolu) Neojen Öncesi Tektonik Birlikler ve Bölgenin Jeodinamik Evrimine Yeni Bir Bakış, TÜBITTAK ÇAYDAG110Y281 Nolu Proje Raporu.

Yiğitbaş, E., Tunç, İ.O., Özkara, Ö., 2018a. Sakarya Zonunun Kuzeybatı Kesimlerinde Alt Karakaya Kompleksi ve Nilüfer Biriminin Yaşı, Stratigrafik ve Yapısal Nitelikleri ve Jeolojik Anlamı. TÜBITAA ÇAYDAG-115Y214 Nolu Proje Raporu.

Yiğitbaş, E., Tunç, İ.O., Özkara, Ö., 2018b. Sakarya Zonunda Paleo-Tetis ile Karakaya Kompleksinin Zaman Mekan İlişsisi ve Bunun Tektonik Anlamı, 71. Türkiye Jeoloji Kurultay1, 23-27 Nisan 2018, Ankara, Türkiye, 42-44.

Yılmaz Şahin, S., Aysal, N., Güngör, Y., Peytcheva, I., Neubauer, F., 2014. Geochemistry and U$\mathrm{Pb}$ zircon geochronology of metagranites in Istranca (Strandja) Zone, NW Pontides, Turkey: Implications for the geodynamic evolution of Cadomian orogeny. Gondwana Research, 26 (2), 755-771. 